\title{
Unicompartmental knee arthroplasty: A PearlDiver study evaluating complications rates, opioid use and utilization in the Medicare population
}

Brandon L. Morris, Jack M. Ayres ${ }^{*}$, Daniel Reinhardt, Armin Tarakemeh, Scott Mullen, J. Paul Schroeppel and Bryan G. Vopat

\begin{abstract}
Purpose: Despite increased utilization of unicompartmental knee arthroplasty (UKA) for unicompartmental knee osteoarthritis, outcomes in Medicare patients are not well-reported. The purpose of this study is to analyze practice patterns and outcome differences between UKA and TKA in the Medicare population. It is hypothesized that UKA utilization will have increased over the course of the study period and that UKA will be associated with reduced opioid use and lower complication rates compared to TKA.

Methods: Using PearlDiver, the Humana Claims dataset and the Medicare Standard Analytic File (SAF) were analyzed. Patients who underwent UKA and TKA were identified by CPT codes. Postoperative complications were identified by ICD-9/ICD-10 codes. Opioid use was analyzed by the number of days patients were prescribed opioids postoperatively. Survivorship was defined as conversion to TKA.

Results: In the Humana dataset, 7,808 UKA and 150,680 TKA patients were identified. 8-year survivorship was 87.7\% (95\% Cl $[0.861,0.894])$. Postoperative opioid use was significantly higher after TKA (186.1 days) compared to UKA (144.7 days) $(p<0.01, \Delta=41.1,95 \% \mathrm{Cl}=[30.41,52.39])$. In the SAF dataset, 20,592 UKA patients and 110,562 TKA patients were identified. Survivorship was highest in patients $>80$ years old and lowest in patients $<70$ years old. In both datasets, postoperative complication rates were higher in TKA patients compared to UKA patients in nearly all categories.
\end{abstract}

Conclusions: UKA represents an increasingly utilized treatment for osteoarthritis in the Medicare population and may be comparatively advantageous to TKA due to reduced opioid use and complication rates after surgery.

Level of evidence: Level III

Keywords: Unicompartmental knee arthroplasty, Total knee arthroplasty, Opioid, Postoperative complication, Medicare, Database

\section{Background}

Unicompartmental knee arthroplasty (UKA) represents a surgical treatment option for patients who present with

${ }^{*}$ Correspondence: jayres@kumc.edu

Department of Orthopedic Surgery, University of Kansas Medical Center, 3901 Rainbow Bvld, Kansas City, KS 66160, USA unicompartmental knee osteoarthritis (OA). Medicare beneficiaries undergoing joint arthroplasty procedures has increased as the United States population has aged [7]. Additionally, there is an increasing incidence of patients with unicompartmental knee arthritis that present at an age and activity level less than ideal for a total knee arthroplasty (TKA) [15]. UKA represents a less-invasive 
alternative to TKA for many of these patients [1, 2]. Coupled with improved instrumentation and understanding of surgical technique, utilization of UKA in recent years has accelerated [10]. What remains unknown is the extent to which patients in the Medicare population are electing to proceed with UKA in lieu of TKA.

Reported advantages of UKA as compared to TKA include bone stock preservation, less surgical exposure and shorter operating time, improved post-operative knee motion and kinematics, lower blood loss and transfusion rates, lower infection rates, shorter inpatient stay, accelerated rehabilitation, and lower implant costs [1]. Indications for UKA include lower activity demand patients, functional and painless knee range of motion, preserved joint alignment and stability, correctible axial malalignment and lack of significant patellofemoral or contra-compartmental osteoarthritis [2,13].

Survivorship studies have demonstrated promising UKA survival data with predictable outcomes in patients undergoing conversion to total knee arthroplasty: a 2010 literature review reports 10-year survivorship at singlecenter studies to be between 95 and $98 \%$ and 15-year survivorship between 85 and 96\% [6]. Despite these advantages, UKA utilization and survivability remains unknown within the Medicare population. The purpose of this study is to analyze UKA practice patterns in the Medicare population and analyze implant survival, opioid use and postoperative complication rates between UKA and TKA. It is hypothesized that UKA utilization will have increased over the course of the study period and that UKA will be associated with reduced opioid use and lower complication rates compared to TKA.

\section{Methods}

In this study, two datasets were examined utilizing the PearlDiver Application. The PearlDiver database is a publicly available, Health Insurance Portability and Accountability Act (HIPAA)-compliant national database containing Current Procedural Terminology (CPT), International Classification of Diseases, Ninth Revision (ICD-9), and International Classification of Diseases, Tenth Revision (ICD-10) codes related to orthopedic procedures. Institutional review board approval was not required for the study. The first dataset is the Humana Claims dataset which contains all medical, pharmaceutical and lab claims from 24.27 million Humana patients from 2007 through March 2017. The Humana dataset contains commercially-insured as well as Medicare patients, therefore search queries were filtered such that we analyzed patients with Medicare Advantage plans through Humana. The second dataset is the Medicare Standard Analytic File (SAF) which contains information of 51 million Medicare patients from 2005 to 2014 based on inpatient and outpatient facility billing records. Since Medicare Advantage patients in the Humana dataset are also listed in the SAF dataset, results are reported by dataset to optimize data accuracy.

UKA patients were identified by CPT-27446, which captures medial or lateral compartment UKAs. TKA patients were identified by CPT-27445 and CPT-27447. Knee arthroplasty revisions were identified by CPT-27486 and CPT-27487. Year of surgery, demographic data, complications as reported by ICD-9 and ICD-10 coding (Appen$\operatorname{dix} C$ ), and comorbidity index scores (Appendix A) were extracted from the datasets. Demographic data included patient age at the time of surgery, gender and region. Regions were defined by Midwest: IA, KS, MN, MO, NE, IL, IN, MI, WI, OH, ND, SD; Northeast: CT, MA, ME, NH, NJ, PA, RI, NY, VT; South: AL, AR, DC, DE, FL, GA, KY, LA, MD, MS, NC, OK, SC, TN, TX, VA, WV, PR; and West: AK, AZ, CA, CO, ID, MT, NM, NV, OR, UT, WA, WY, HI.

Elixhauser and Charlson comorbidity measures are well-known risk adjustment models commonly used for "adjustment of quality and safety data" [14]. These scores were calculated for each patient and reported in aggregate for each group in each database in order to compare the relative health of each population. The comorbidities included in each calculation and methodology is explained in Appendix A.

Opioid use was calculated by identifying filled postoperative opioid prescriptions (listed in Appendix B). Because pharmaceutical information is not available in the SAF dataset, opioid use analysis was not performed on that data set.

Statistical analysis was performed using qualitative analysis and logistic regression. $\mathrm{P}$ values of $<0.05$ were considered significant. Statistical analysis on opioid use and time between UKA and TKA/revision were performed with use of the Pearl Diver Bellwether application. For statistical analysis using proportions of UKA/ TKA patients experiencing an event (such as complication or revision), Chi-square tests were conducted using R[v 3.6.3]. Elixhauser and Charlson scores were analyzed using Mann-Whitney $\mathrm{U}$ tests in $\mathrm{R}[\mathrm{v}$ 3.6.3]. For the time between UKA and TKA and the time until revision, z-tests were used and difference with regards to age ranges were analyzed using ANOVA in R[v 3.6.3]. Survivability was defined as conversion to TKA and Kaplan-Meier survival curves were generated by the PearlDiver Bellwether application. Kaplan-Meier survival curves were then compared using a log rank test which approximates a $\mathrm{X}^{2}$ test statistic for which $\mathrm{X}^{2}$ values greater than the reference value of 3.84 are considered significant. 


\section{Humana results}

\section{UKA utilization and demographics}

Between 2007 and March 2017, 7,808 patients underwent UKA in the Medicare Advantage population (Table 1). 150,680 patients underwent TKA in the same time period. Annual utilization trends varied during the study period (Table 2). Though TKA was performed more commonly in every year as compared to UKA, UKA utilization generally increased over time from 264 cases in 2007 to 1,382 in 2015. During this time period, the percentage of UKA cases compared to UKA and TKA cases combined rose from $3.79 \%$ to $4.96 \%$ (Table 2; Fig. 1).

Patients aged 70-74 years accounted for the most UKA procedures $(2,303)$, followed by patients aged $65-69$ years $(2,208)$ (Table 1). Gender utilization was $54 \%$ female and $46 \%$ male. Geographically, most procedures were performed in the South (60\%). Age profile and geographic predominance were similar to the TKA group; however, $64 \%$ of patients who underwent TKA were women.

The median Elixhauser adjustment for TKA is 7 compared to 6 for UKA $(p<0.01)$. There was a statistically significant difference in Charlson scores $(p<0.01)$ (Table 3$)$.

Table 1 All patients who underwent UKA and TKA during the study period

\begin{tabular}{|c|c|c|c|c|}
\hline \multirow{3}{*}{ Total } & \multirow{2}{*}{\multicolumn{2}{|c|}{$\frac{\text { UKA }}{7,808}$}} & \multirow{2}{*}{\multicolumn{2}{|c|}{$\frac{\text { TKA }}{150,680}$}} \\
\hline & & & & \\
\hline & $\#$ & $\%$ & $\overline{\#}$ & $\%$ \\
\hline \multicolumn{5}{|l|}{ Age } \\
\hline 64 and under & 977 & $13 \%$ & 21,325 & $14 \%$ \\
\hline $65-69$ & 2,208 & $28 \%$ & 40,708 & $27 \%$ \\
\hline $70-74$ & 2,303 & $29 \%$ & 42,825 & $28 \%$ \\
\hline $75-79$ & 1,427 & $18 \%$ & 30,510 & $20 \%$ \\
\hline $80-84$ & 723 & $9 \%$ & 15,273 & $10 \%$ \\
\hline 85 and older & 304 & $4 \%$ & 6,104 & $4 \%$ \\
\hline \multicolumn{5}{|l|}{ Region } \\
\hline Midwest & 2,198 & $28 \%$ & 43,775 & $29 \%$ \\
\hline Northeast & 183 & $2 \%$ & 4,167 & $3 \%$ \\
\hline South & 4,678 & $60 \%$ & 87,067 & $58 \%$ \\
\hline West & 750 & $10 \%$ & 15,718 & $10 \%$ \\
\hline \multicolumn{5}{|l|}{ Gender } \\
\hline Female & 4,216 & $54 \%$ & 96,536 & $64 \%$ \\
\hline Male & 3,592 & $46 \%$ & 54,144 & $36 \%$ \\
\hline \multicolumn{5}{|l|}{ Race } \\
\hline White & 6,547 & $84 \%$ & 119,440 & $79 \%$ \\
\hline Black & 345 & $4 \%$ & 14,487 & $10 \%$ \\
\hline Asian & 34 & $0 \%$ & 656 & $0 \%$ \\
\hline Hispanic & 53 & $1 \%$ & 1,565 & $1 \%$ \\
\hline Native American & 14 & $0 \%$ & 341 & $0 \%$ \\
\hline Other & 75 & $1 \%$ & 1,522 & $1 \%$ \\
\hline Unknown & 740 & $9 \%$ & 12,669 & $8 \%$ \\
\hline
\end{tabular}

Table 2 Number of patients undergoing UKA or TKA by year

\begin{tabular}{lllll}
\hline & UKA & TKA & TKA:UKA & \%UKA of cases \\
\hline 2007 & 264 & 6709 & 25.41 & $3.79 \%$ \\
2008 & 458 & 8793 & 19.20 & $4.95 \%$ \\
2009 & 506 & 10,405 & 20.56 & $4.64 \%$ \\
2010 & 641 & 12,960 & 20.22 & $4.71 \%$ \\
2011 & 625 & 14,637 & 23.42 & $4.10 \%$ \\
2012 & 728 & 15,976 & 21.95 & $4.36 \%$ \\
2013 & 911 & 19,697 & 21.62 & $4.42 \%$ \\
2014 & 1233 & 22,793 & 18.49 & $5.13 \%$ \\
2015 & 1382 & 26,480 & 19.16 & $4.96 \%$ \\
2016 & 1172 & 22,603 & 19.29 & $4.93 \%$ \\
Annualized 2017 & 1216 & 23,400 & 19.24 & $4.94 \%$ \\
\hline
\end{tabular}

\section{UKA conversion and revision}

Table 4 shows data from the Humana dataset related to UKA conversion to TKA. 358 UKA (4.59\%) patients underwent conversion to TKA with an average time between UKA and TKA of 817 days (Standard deviation $(\mathrm{SD})=699.070)$. Female patients were not significantly more likely to undergo conversion to TKA at $5.00 \%$ compared to $4.09 \%$ of men $(p=0.055, \mathrm{RR}=0.818$, $95 \% \mathrm{CI}=[0.667,1.005)$, however, time between UKA and TKA conversion was significantly longer for female patients (852 days) compared to male patients (767 days) $(p<0.001, \Delta=85.1,95 \% \mathrm{CI}=[53.5,119.8])$. Conversion to total knee arthroplasty occurred more commonly in patients under the age of 70 with $6.07 \%$ of patients undergoing conversion compared to $4.06 \%$ of patients ages $70-79(p<0.01, \mathrm{RR}=0.67,95 \% \mathrm{CI}=[0.54,0.82])$ and $1.57 \%$ of patients over $80(p<0.01, \mathrm{RR}=0.26,95 \%$ $\mathrm{CI}=[0.16,0.43])$. Regarding time between UKA and reversion to TKA, the ANOVA test for differences in age showed a significant result $(p<0.001)$. Patients under 70 had longer times between UKA and conversion to TKA than patients aged 70-79 $(\Delta=75.8,95 \% \mathrm{CI}=[44.1$, 107.5]) and patients over $80(\Delta=171.2,95 \% \mathrm{CI}=[124.2$, 218.3]). Patients 70-79 also had longer times between UKA and conversion to TKA than patients over 80 $(\Delta=95.4,95 \% \mathrm{CI}=[49.02,141.7])$.

Overall 8-year UKA implant survival was $87.7 \%$ (95\% CI [0.861,0.894]) (Fig. 2).

Table 5 shows data from the Humana dataset related to revision surgeries for both TKA and UKA. Revision was more common after UKA than TKA as 303 UKA patients $(3.88 \%)$ underwent a revision and 3,921 TKA patients $(2.60 \%)$ underwent a revision $(p<0.01$, $\mathrm{RR}=1.49$, 95\% $\mathrm{CI}=[1.33,1.67])$. Additionally, revision occurred later following UKA compared to TKA in patients who underwent revision. Average time between TKA and revision was 608 days $(\mathrm{SD}=603.241)$ 


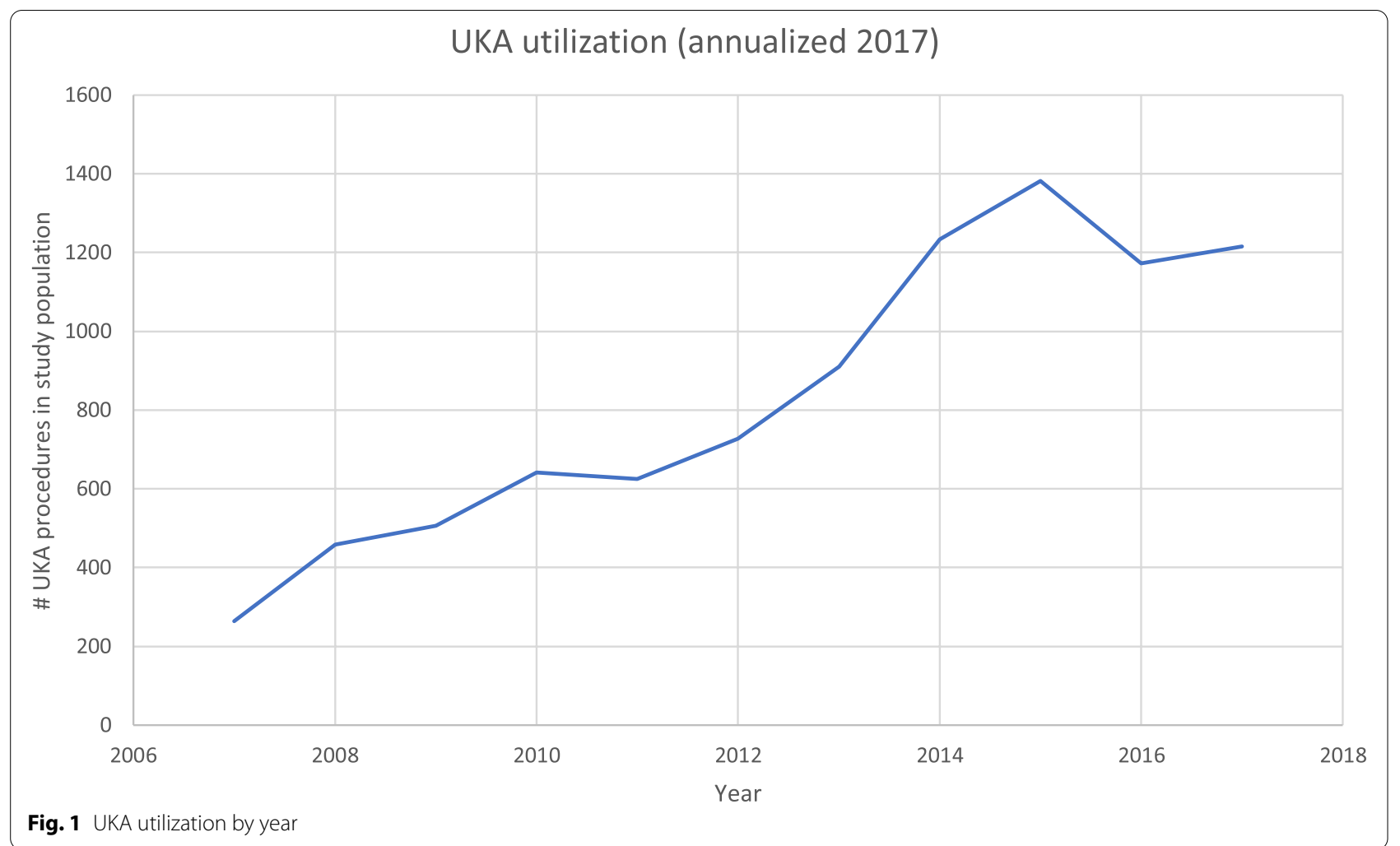

days, whereas average time between UKA and revision was 718 days $(\mathrm{SD}=691.332)(p<0.001, \Delta=110.7,95 \%$ $\mathrm{CI}=[95.1,126.3])$. Out of the 7,808 UKA patients, 358 were converted to TKA, 303 were revised, and 49 were both converted and revised.

In the UKA group, no significant difference was found between male and female patients regarding revision rate $(p=0.270 \mathrm{RR}=0.882,95 \% \mathrm{CI}=[0.706,1.012])$ or time between UKA and revision $(p=0.133, \Delta=17.6$, 95\% CI $=[-13.4,48.6]$ ) (Table 5). Regarding age for UKA patients, patients under 70 years old had no significant difference in times between UKA and conversion to TKA from those ages $70-79(\Delta=-26.8,95 \% \mathrm{CI}=[-59.8$, 6.2]), but longer times between UKA and conversion to TKA than those over 80 years $(\Delta=59.7,95 \% \mathrm{CI}=[10.7$, 108.7]). Patients ages 70-79 also had longer times between UKA and conversion to TKA than those over 80 years old $(\Delta=86.5,95 \% \mathrm{CI}=[38.3,134.7])$.

In the TKA group, the revision rate was not significantly different between male and female patients $(p=0.301, \mathrm{RR}=1.073,95 \% \mathrm{CI}=[1.001,1.144])$, however, the time between TKA and revision was longer in female patients compared to male patients $(p<0.001, \Delta=55.6$, $95 \% \mathrm{CI}=[49.4,61.7])$. The TKA group had significant differences with regards to all age groups. Patients under 70 years old had longer times between UKA and conversion to TKA than those ages $70-79(\Delta=43.0,95 \%$
$\mathrm{CI}=[36.3,49.6])$ and over 80 years old $(\Delta=92.4,95 \%$ $\mathrm{CI}=[82.7,102.0])$, while patients ages $70-79$ also had longer times between UKA and conversion to TKA than those over 80 years old $(\Delta=49.4,95 \% \mathrm{CI}=[39.9,58.8])$.

\section{Opioid use}

Of the 7,808 patients who underwent UKA, 5,605 patients $(71.79 \%)$ filled prescriptions for opioids for an average of 144.7 days after surgery (Table 6). Of the 150,680 patients who underwent TKA, 114,583 patients (76.04\%) filled prescriptions for an average of 186.1 days after surgery $(p<0.001, \Delta=41.1,95 \% \mathrm{CI}=[52.4,30.4])$ (Table 6).

\section{Complications}

Complications occurred at a significantly higher rate in all categories except capsulitis $(p=0.266)$ in the TKA group compared to the UKA group (Table 7). This includes cardiovascular complications such as DVT $(p=0.022)$ and cardiac arrest $(p=0.008)$, as well as wound dehiscence $(p<0.001)$ (Table 7).

\section{Medicare Standard Analytic File results UKA utilization and demographics}

Between 2005 and 2014, a total of 20,592 patients underwent UKA procedures (Table 8). 110,562 patients 
Table 3 Elixhauser and Charlson comorbidity adjustment scores for UKA and TKA

\begin{tabular}{|c|c|c|c|c|}
\hline \multirow[t]{3}{*}{ Adjustment score } & \multicolumn{2}{|c|}{ Elixhauser } & \multicolumn{2}{|c|}{ Charlson } \\
\hline & UKA & TKA & UKA & TKA \\
\hline & \multicolumn{4}{|c|}{$\begin{array}{l}\text { \# of patients with the Elixhauser/Charlson } \\
\text { score }\end{array}$} \\
\hline 0 & 101 & 968 & 2,753 & 44,544 \\
\hline 1 & 303 & 3,636 & 1,760 & 34,437 \\
\hline 2 & 578 & 7,145 & 1,200 & 23,837 \\
\hline 3 & 733 & 10,288 & 799 & 17,062 \\
\hline 4 & 762 & 12,711 & 470 & 10,540 \\
\hline 5 & 800 & 13,670 & 285 & 7,207 \\
\hline 6 & 732 & 13,719 & 205 & 4,723 \\
\hline 7 & 686 & 13,492 & 106 & 2,930 \\
\hline 8 & 577 & 12,395 & 106 & 2,052 \\
\hline 9 & 501 & 11,257 & 47 & 1,271 \\
\hline 10 & 450 & 10,012 & 34 & 792 \\
\hline 11 & 389 & 8,832 & 17 & 489 \\
\hline 12 & 294 & 7,509 & 11 & 291 \\
\hline 13 & 252 & 6,411 & - & 184 \\
\hline 14 & 190 & 5,198 & - & 125 \\
\hline 15 & 153 & 4,135 & - & 88 \\
\hline 16 & 99 & 3,019 & - & 52 \\
\hline 17 & 90 & 2,236 & - & 24 \\
\hline 18 & 51 & 1,581 & - & - \\
\hline 19 & 23 & 1,084 & - & - \\
\hline 20 & 22 & 651 & - & - \\
\hline 21 & 11 & 385 & - & - \\
\hline 22 & - & 191 & - & - \\
\hline 23 & - & 106 & - & - \\
\hline 24 & - & 35 & - & - \\
\hline \multirow[t]{2}{*}{25} & - & 11 & - & - \\
\hline & \multicolumn{4}{|c|}{ Overall } \\
\hline Average & 7.04 & 8.06 & 1.79 & 2.07 \\
\hline Median & 6.00 & 7.00 & 1.00 & 1.00 \\
\hline St. dev & 4.18 & 4.35 & 2.17 & 2.33 \\
\hline$p$ & \multicolumn{2}{|c|}{$<0.0001$} & \multicolumn{2}{|c|}{$<0.0001$} \\
\hline
\end{tabular}

underwent TKA in the same time period. Annual utilization trends varied during the study period with the most dramatic increase in UKA utilization occurring in years 2012-2014 (Fig. 3). TKA was performed more commonly in every year compared to UKA, although TKA did not show as large of a rate of increase as UKA during the last three years of the study period. UKA made up an increasing proportion of overall knee arthroplasty volume toward the end of the study period, as nearly $1 / 3 \mathrm{rd}$ of knee arthroplasty procedures performed in 2014 were UKA (Fig. 3).
The largest portion of patients undergoing UKA were aged 65-69 years $(6,319)$, followed by patients aged $70-74$ years $(5,518)$ (Table 8). Gender utilization was $51 \%$ female and $48 \%$ male. Geographically, most procedures were performed in the South (52\%). Age group and geographic predominance were similar to the TKA group; however, $65 \%$ of patients who underwent TKA were women (35\% men).

The median Elixhauser adjustment for TKA is 9 compared to 5 for UKA $(p<0.01)$. The median Charlson adjustment for TKA is 2 compared to 1 for UKA $(p<0.01)$ (Table 9).

\section{UKA conversion and revision}

Table 10 shows data from the SAF dataset related to UKA conversion to TKA. 447 (2.17\%) UKA patients underwent subsequent TKA and the average time between UKA and TKA was 987 days $(\mathrm{SD}=764.815)$ (2.71 years). Male patients were less likely to undergo conversion to TKA at $1.70 \%$ compared to $2.50 \%$ of women $(p<0.01, \mathrm{RR}=0.68$, $95 \% \mathrm{CI}=[0.56,0.82])$. However, the time between UKA and conversion was not statistically different between female and male patients $(p=0.287, \Delta=6.02,95 \%$ $\mathrm{CI}=[-14.98,27.03])$. Conversion occurred more commonly in patients under the age of 70 with $2.78 \%$ of patients undergoing conversion compared to $1.78 \%$ of patients ages $70-79(p<0.01, \mathrm{RR}=0.64,95 \% \mathrm{CI}=[0.53$, $0.78])$ and $1.35 \%$ of patients over 80 years old $(p<0.01$, $\mathrm{RR}=0.48,95 \% \mathrm{CI}=[0.35,0.67])($ Table 10$)$. Analysis of time between UKA and TKA for age showed no significant difference between patient under 70 years old and patients ages $70-79(\Delta=8.6,95 \% \mathrm{CI}=[-13.9,31.1])$. However, patients over 80 years old had shorter times between UKA and conversion to TKA than both patients under 70 years old $(\Delta=182.3,95 \% \mathrm{CI}=[151.3,213.3])$ and patients ages $70-79(\Delta=173.7,95 \% \mathrm{CI}=[143.4$, 204.1]).

UKA implant survival was $91.1 \%$ (95\% CI [0.895,0.928]) (Fig. 4; Table 11) at 8 years. Implant survival increased with advancing age $\left(X^{2}=4.66\right)$. The highest rate of survival was seen in patients over 80-years-old $(95.6 \%$ $(95 \% \mathrm{CI}[0.926,0.992]))$ and the lowest in patients under 70 -years-old $(89.3 \%$ (95\% CI [0.865,0.921])) (Table 11).

Table 12 shows data from the SAF dataset related to revision surgeries for both TKA and UKA. Revision was less common after UKA than TKA as 364 UKA patients (1.77\%) underwent a revision and 3,630 TKA patients (3.28\%) underwent a revision $(p<0.001, \mathrm{RR}=0.53,95 \%$ $\mathrm{CI}=[0.48,0.59])$. The percentage of patients who underwent a revision is higher in the UKA group than it is in the TKA group, among all age classes and genders. The difference in time to revision between UKA and TKA 
Table 4 Time between UKA and TKA for patients undergoing conversion

\begin{tabular}{|c|c|c|c|c|c|c|c|c|c|}
\hline & \multirow{2}{*}{$\begin{array}{l}\text { Number of } \\
\text { UKA patients } \\
\#\end{array}$} & \multicolumn{5}{|c|}{ UKA patients who underwent conversion to TKA } & \multicolumn{3}{|c|}{$\begin{array}{l}\text { Average time between UKA and TKA for patients } \\
\text { undergoing conversion }\end{array}$} \\
\hline & & $\#$ & $\%$ & $\mathbf{p}$ & RR & $95 \% \mathrm{Cl}$ & Days & $\Delta$ & $95 \% \mathrm{Cl}$ \\
\hline Total & 7,808 & 358 & $4.59 \%$ & - & - & - & 816.997 (SD 699.070) & - & - \\
\hline \multicolumn{10}{|c|}{ Age at UKA } \\
\hline$<70$ & 3,180 & 193 & $6.07 \%$ & - & - & - & 857.802 (SD 757.430) & - & - \\
\hline $70-79$ & 3,694 & 150 & $4.06 \%$ & $<0.0001$ & 0.6691 & $(0.5434,0.8238)$ & 782.020 (SD 641.146) & 75.802 & $(44.144,107.460)$ \\
\hline$>80$ & 1,021 & 16 & $1.57 \%$ & $<0.0001$ & 0.2582 & $(0.1558,0.4278)$ & 686.563 (SD 414.917) & 171.239 & $(124.164,218.314)$ \\
\hline \multicolumn{10}{|l|}{ Gender } \\
\hline Female & 4,216 & 211 & $5.00 \%$ & - & - & - & 851.957 (SD 659.386) & - & - \\
\hline Male & 3,592 & 147 & $4.09 \%$ & 0.0547 & 0.8177 & $(0.6656,1.0048)$ & 766.816 (SD 751.853) & 85.141 & $(53.5070,119.7749)$ \\
\hline
\end{tabular}

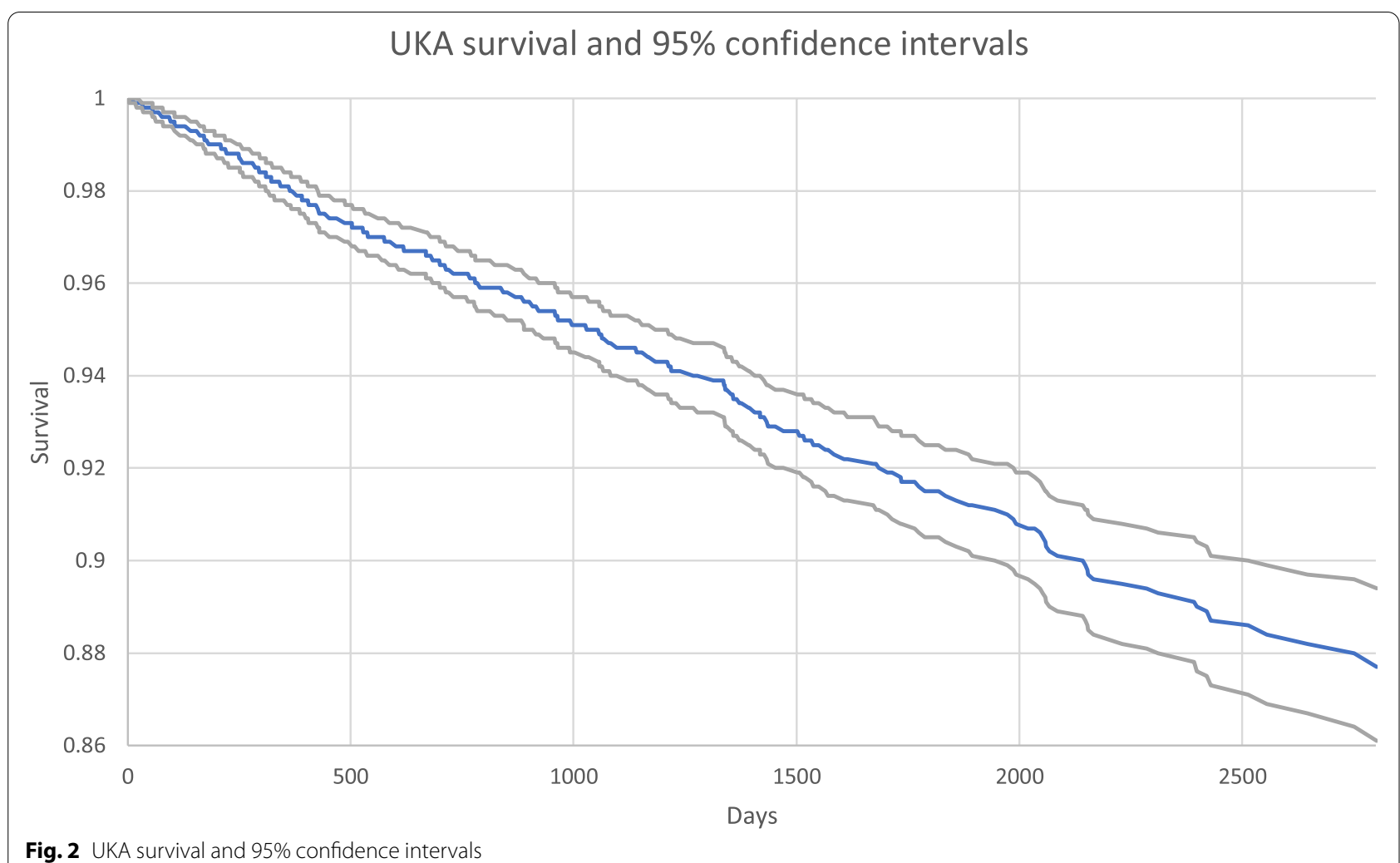

patients who underwent revision was statistically significant $(p<0.001, \Delta=66.3,95 \% \mathrm{CI}=[54.9,77.7])$. The overall average time between TKA and revision was 867 $(\mathrm{SD}=754)$ and the overall average time between UKA and revision was $933(\mathrm{SD}=768)$ days (Table 12). Of the 20,592 UKA patients, 447 were converted to TKA, 364 were revised, and 67 were both converted and revised.

In the UKA group, the revision rate for male patients was lower than female patients $(p<0.01, \mathrm{RR}=0.64$, $95 \% \mathrm{CI}=[0.52,0.79])$, and revision occurred sooner for male patients compared to female patients $(p<0.001$, $\Delta=158.1,95 \% \mathrm{CI}=[137.4,178.9])$. UKA patients under 70 years old had less time between UKA and revision than those ages $70-79(\Delta=-176.7,95 \% \mathrm{CI}=[-199.3$, -154.2]), but more time between UKA and revision than those over 80 years old $(\Delta=73.2,95 \% \mathrm{CI}=[42.1,104.3])$. Patients ages 70-79 had more time between UKA and revision than patients over 80 years old $(\Delta=250.0,95 \%$ $\mathrm{CI}=[219.5,280.4])$. 
Table 5 Time until revision for UKA and TKA

\begin{tabular}{|c|c|c|c|c|c|c|c|c|c|}
\hline & \multirow{2}{*}{$\begin{array}{l}\text { UKA } \\
\text { Patients }\end{array}$} & \multicolumn{5}{|c|}{ UKA revisions } & \multicolumn{3}{|c|}{ Avg. time between UKA and revision } \\
\hline & & $\#$ & $\%$ & $p$ & $\mathrm{RR}$ & $95 \% \mathrm{Cl}$ & Mean (SD) & $\Delta$ & $95 \% \mathrm{Cl}$ \\
\hline Total & 7,808 & 303 & $3.88 \%$ & - & - & - & 718.535 (SD 691.332) & - & - \\
\hline \multicolumn{10}{|c|}{ Age at UKA } \\
\hline$<70$ & 3,180 & 166 & $5.22 \%$ & - & - & - & $715.880($ SD 653.431$)$ & - & - \\
\hline 70-79 & 3,694 & 111 & $3.00 \%$ & $<0.0001$ & 0.5756 & $(0.4548,0.7285)$ & 742.694 (SD 755.353) & -26.814 & $(-59.798,6.170)$ \\
\hline$>80$ & 1,021 & 28 & $2.74 \%$ & $<0.0001$ & 0.5254 & $(0.3542,0.7792)$ & 656.179 (SD 589.094) & 59.7 & $(10.7,108.7)$ \\
\hline \multicolumn{10}{|l|}{ Gender } \\
\hline Female & 4,216 & 173 & $4.10 \%$ & - & - & - & 726.509 (SD 677.448) & - & - \\
\hline \multirow[t]{3}{*}{ Male } & 3,592 & 130 & $3.62 \%$ & 0.2695 & 0.882 & $(0.7056,1.01024)$ & 708.923 (SD 711.889) & 17.586 & $(-13.4002,48.5722)$ \\
\hline & TKA & \multicolumn{5}{|c|}{ TKA revisions } & \multicolumn{3}{|c|}{ Avg. time between TKA and revision } \\
\hline & patients & $\#$ & $\%$ & $p$ & RR & $95 \% \mathrm{Cl}$ & Mean (SD) & $\Delta$ & $95 \% \mathrm{Cl}$ \\
\hline Total & 150,680 & 3,921 & $2.60 \%$ & - & - & - & 607.849 (SD 603.241) & - & - \\
\hline \multicolumn{10}{|c|}{ Age at TKA } \\
\hline$<70$ & 61,030 & 2,177 & $3.57 \%$ & - & - & - & 647.463 (SD 620.240) & - & - \\
\hline $70-79$ & 71,702 & 1,510 & $2.11 \%$ & $<0.0001$ & 0.5904 & $(0.5534,0.6297)$ & 604.472 (SD 613.365) & 42.991 & $(36.345,49.637)$ \\
\hline$>80$ & 21,081 & 364 & $1.73 \%$ & $<0.0001$ & 0.4841 & $(0.4337,0.5403)$ & 555.085 (SD 610.039) & 92.378 & $(82.738,102.018)$ \\
\hline \multicolumn{10}{|l|}{ Gender } \\
\hline Female & 96,536 & 2,448 & $2.54 \%$ & - & - & - & 632.112 (SD 626.075) & - & - \\
\hline Male & 54,144 & 1,473 & $2.72 \%$ & 0.3007 & 1.0728 & $(1.0066,1.1435)$ & 576.525 (SD 561.138) & 55.587 & $(49.4276,61.7464)$ \\
\hline
\end{tabular}

Table 6 Days of opioid use following TKA and UKA

\begin{tabular}{|c|c|c|}
\hline & UKA & TKA \\
\hline Number of patients & $\begin{array}{l}5,605 \text { (71.79\% of pts } \\
\text { who underwent UKA) }\end{array}$ & $\begin{array}{l}114,583 \text { ( } 76.04 \% \text { of } \\
\text { pts who underwent } \\
\text { TKA) }\end{array}$ \\
\hline \multicolumn{3}{|l|}{ Number of days filled: } \\
\hline Mean & 144.7 & 186.1 \\
\hline Standard deviation & 408.02 & 449.63 \\
\hline$p$-value & $<0.0001$ & \\
\hline $95 \% \mathrm{Cl}$ & $(52.3944,30.4056)$ & \\
\hline
\end{tabular}

In the TKA group, there was no difference between male and female revision rate $(p=0.835, \mathrm{RR}=0.99,95 \%$ $\mathrm{CI}=[0.93,1.06])$, but the time between TKA and revision was longer in female patients compared to male patients $(p<0.001, \Delta=82.5,95 \% \mathrm{CI}=[73.2,91.9])$. Times between TKA and revision for patients under 70 years old were not significantly different from those ages 70-79 $(\Delta=-9.5,95 \% \mathrm{CI}=[-19.2,0.3])$, however, patients under 70 years old had longer times between TKA and revision than patients over 80 years old $(\Delta 180.4,95 \% \mathrm{CI}=[167.5$, 193.2]). Patients ages 70-79 also had more time between

Table 7 Incidence of complications within 12 months following TKA and UKA

\begin{tabular}{|c|c|c|c|c|c|c|c|}
\hline \multirow[t]{2}{*}{ Complication } & \multicolumn{2}{|l|}{ UKA } & \multicolumn{2}{|l|}{ TKA } & \multirow[t]{2}{*}{$p$} & \multirow[t]{2}{*}{ RR } & \multirow[t]{2}{*}{$95 \% \mathrm{Cl}$} \\
\hline & $\#$ & $\%$ & $\#$ & $\%$ & & & \\
\hline Acute kidney injury & 248 & $3.18 \%$ & 9,078 & $6.02 \%$ & $<0.0001$ & 0.5581 & $(0.4930,0.6318)$ \\
\hline Cardiac arrest & 25 & $0.32 \%$ & 823 & $0.55 \%$ & 0.0082 & 0.5893 & $(0.3961,0.8767)$ \\
\hline Deep vein thrombosis & 42 & $0.54 \%$ & 1,168 & $0.78 \%$ & 0.0215 & 0.6991 & $(0.5143,0.9503)$ \\
\hline Pneumonia & 280 & $3.59 \%$ & 7,891 & $5.24 \%$ & $<0.0001$ & 0.7194 & $(0.6399,0.8086)$ \\
\hline Pulmonary embolism & 99 & $1.27 \%$ & 3,012 & $2.00 \%$ & $<0.0001$ & 0.6466 & $(0.5299,0.7888)$ \\
\hline Urinary tract infection & 1,109 & $14.20 \%$ & 28,445 & $18.88 \%$ & $<0.0001$ & 0.8889 & $(0.8409,0.9397)$ \\
\hline Wound deshiscence & 82 & $1.05 \%$ & 2,407 & $1.60 \%$ & 0.0003 & 0.6676 & $(0.5363,0.8310)$ \\
\hline Hematoma & 71 & $0.91 \%$ & 2,245 & $1.49 \%$ & 0.0001 & 0.6191 & $(0.4894,0.7833)$ \\
\hline Transfusion & 82 & $1.05 \%$ & 4,271 & $2.83 \%$ & $<0.0001$ & 0.3808 & $(0.3064,0.4733)$ \\
\hline Capsulitis & 53 & $0.68 \%$ & 1,204 & $0.80 \%$ & 0.2655 & 0.8560 & $(0.6507,1.1260)$ \\
\hline Nerve injury & 0 & $0.00 \%$ & 81 & $0.05 \%$ & 0.0405 & 0 & - \\
\hline
\end{tabular}


Table 8 All patients who underwent UKA and TKA during the study period

\begin{tabular}{|c|c|c|c|c|}
\hline \multirow{3}{*}{ Total } & \multirow{2}{*}{\multicolumn{2}{|c|}{$\begin{array}{l}\text { UKA } \\
20,592\end{array}$}} & \multirow{2}{*}{\multicolumn{2}{|c|}{$\begin{array}{l}\text { TKA } \\
110,562\end{array}$}} \\
\hline & & & & \\
\hline & $\#$ & $\%$ & \# & $\%$ \\
\hline \multicolumn{5}{|l|}{ Age } \\
\hline 64 and under & 1,709 & $8 \%$ & 11,183 & $10 \%$ \\
\hline $65-69$ & 6,319 & $31 \%$ & 30,628 & $28 \%$ \\
\hline $70-74$ & 5,518 & $27 \%$ & 29,247 & $26 \%$ \\
\hline $75-79$ & 4,005 & $19 \%$ & 24,685 & $22 \%$ \\
\hline $80-84$ & 2,250 & $11 \%$ & 14,539 & $13 \%$ \\
\hline 85 and older & 959 & $5 \%$ & 5,534 & $5 \%$ \\
\hline Unknown & 147 & $1 \%$ & 1,681 & $2 \%$ \\
\hline \multicolumn{5}{|l|}{ Region } \\
\hline Midwest & 4,502 & $22 \%$ & 30,816 & $28 \%$ \\
\hline Northeast & 2,736 & $13 \%$ & 17,703 & $16 \%$ \\
\hline South & 10,627 & $52 \%$ & 43,475 & $39 \%$ \\
\hline West & 2,732 & $13 \%$ & 18,777 & $17 \%$ \\
\hline Unknown & 0 & $0 \%$ & 27 & $0 \%$ \\
\hline \multicolumn{5}{|l|}{ Gender } \\
\hline Female & 10,543 & $51 \%$ & 71,394 & $65 \%$ \\
\hline Male & 9,933 & $48 \%$ & 38,214 & $35 \%$ \\
\hline Unknown/Other & 147 & $1 \%$ & 1,681 & $2 \%$ \\
\hline
\end{tabular}

TKA and revision than patients over 80 years old $(\Delta=189.8,95 \% \mathrm{CI}=[177.4,193.2])$.

\section{Complications}

Complications occurred at a higher rate in all categories in the TKA group compared to the UKA group (Table 13). Differences in complication rates between TKA and UKA demonstrated statistical significance $(p<0.01)$ (Table 13).

\section{Discussion}

Unicompartmental knee arthroplasty demonstrated increased utilization between 2005 and 2017 in the Medicare population. Though TKA was performed more commonly in every year as compared to UKA, UKA utilization generally increased over time: In the Humana dataset the UKA cases increased from 264 cases in 2007 to 1,382 in 2015 (Table 2; Fig. 1). In the SAF dataset, nearly $1 / 3$ rd of knee arthroplasty procedures performed in 2014 were UKA (Fig. 3). Analysis of opioid use in the Humana dataset revealed a statistically significant $(p<0.01)$ decrease in the mean number of days for which opioid prescriptions were filled after UKA (145 days) as compared to TKA (186 days). UKA was associated with significantly lower complication rates compared to TKA, including complications such as DVT (Humana:

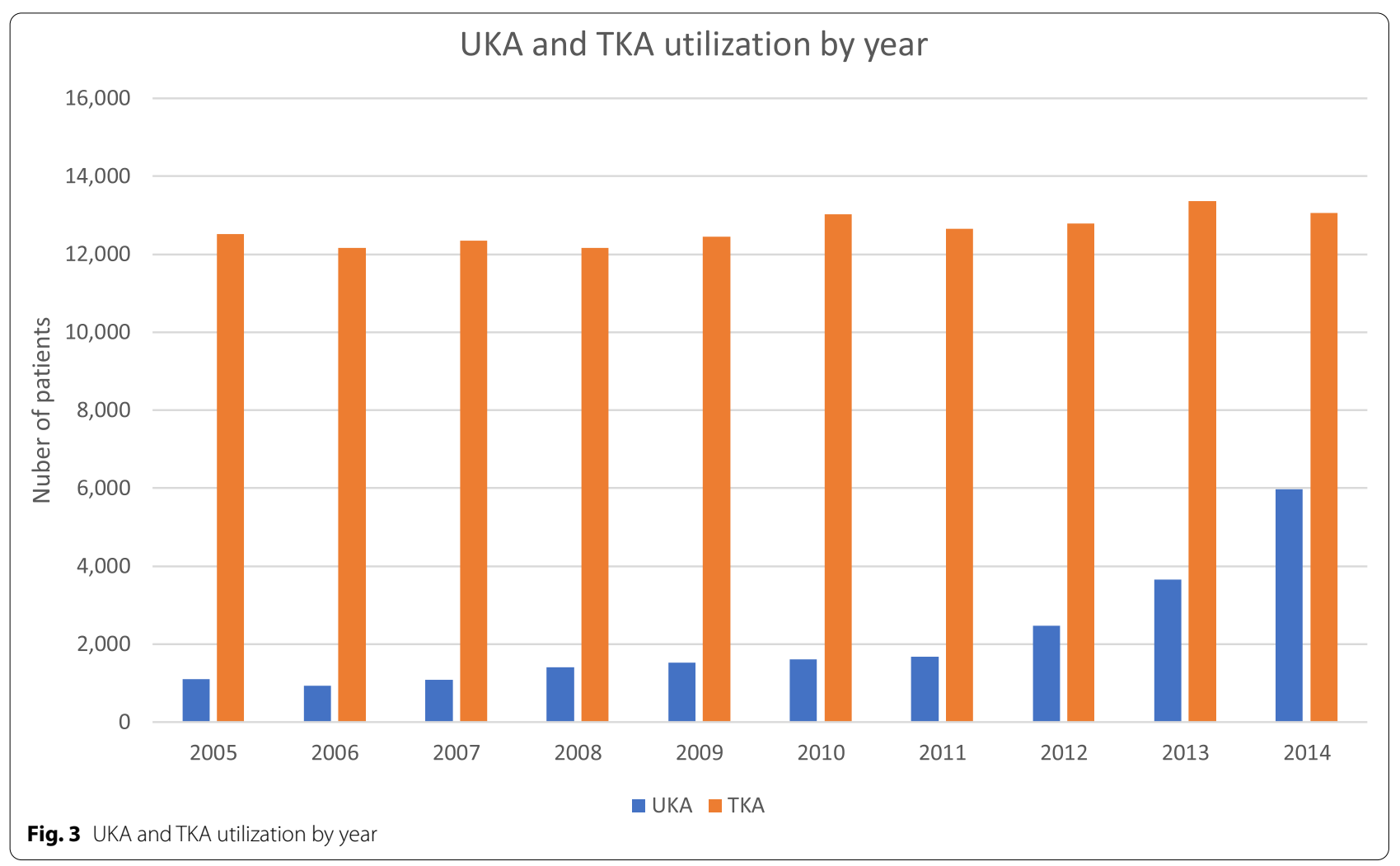


Table 9 Elixhauser and Charlson comorbidity adjustment scores for UKA and TKA

\begin{tabular}{|c|c|c|c|c|}
\hline \multirow[t]{3}{*}{ Adjustment score } & \multicolumn{2}{|c|}{ Elixhauser } & \multicolumn{2}{|c|}{ Charlson } \\
\hline & UKA & TKA & UKA & TKA \\
\hline & \multicolumn{4}{|c|}{$\begin{array}{l}\text { Number of patients with the Elixhauser/ } \\
\text { Charlson score }\end{array}$} \\
\hline 0 & 729 & 504 & 8,358 & 25,981 \\
\hline 1 & 1,749 & 1,861 & 5,177 & 24,946 \\
\hline 2 & 2,418 & 3,580 & 3,071 & 19,094 \\
\hline 3 & 2,493 & 5,510 & 1,698 & 14,143 \\
\hline 4 & 2,287 & 6,914 & 893 & 8,922 \\
\hline 5 & 2,017 & 8,016 & 516 & 5,860 \\
\hline 6 & 1,673 & 8,509 & 301 & 3,663 \\
\hline 7 & 1,452 & 8,747 & 190 & 2,381 \\
\hline 8 & 1,222 & 8,624 & 138 & 1,723 \\
\hline 9 & 935 & 8,415 & 87 & 1,267 \\
\hline 10 & 842 & 7,992 & 69 & 904 \\
\hline 11 & 636 & 7,470 & 42 & 611 \\
\hline 12 & 533 & 6,589 & 22 & 353 \\
\hline 13 & 422 & 5,946 & 12 & 268 \\
\hline 14 & 348 & 5,172 & - & 169 \\
\hline 15 & 262 & 4,259 & - & 126 \\
\hline 16 & 185 & 3,440 & - & 56 \\
\hline 17 & 139 & 2,904 & - & 37 \\
\hline 18 & 100 & 2,197 & - & 27 \\
\hline 19 & 74 & 1,565 & - & 12 \\
\hline 20 & 26 & 1,007 & - & - \\
\hline 21 & 24 & 643 & - & - \\
\hline 22 & 15 & 356 & - & - \\
\hline 23 & - & 199 & - & - \\
\hline 24 & - & 84 & - & - \\
\hline 25 & - & 37 & - & - \\
\hline \multirow[t]{2}{*}{26} & - & 16 & - & - \\
\hline & \multicolumn{4}{|l|}{ Overall } \\
\hline Average & 5.73 & 9.30 & 1.43 & 2.39 \\
\hline Median & 5.00 & 9.00 & 1.00 & 2.00 \\
\hline St. dev & 4.11 & 4.71 & 1.91 & 2.54 \\
\hline$p$ & \multicolumn{2}{|l|}{$<0.0001$} & \multicolumn{2}{|c|}{$<0.0001$} \\
\hline
\end{tabular}

$(p=0.0215, \mathrm{RR}=0.70,95 \% \mathrm{CI}=[0.51,0.95])$ and $\mathrm{SAF}:$ $(p<0.0001, \mathrm{RR}=0.34,95 \% \mathrm{CI}=[0.19,0.59]))$ and cardiac arrest (Humana: $(p=0.0082, \mathrm{RR}=0.59,95 \% \mathrm{CI}=[0.40$, $0.88])$ and SAF: $(p<0.0001, \mathrm{RR}=0.41,95 \% \mathrm{CI}=[0.31$, $0.55])$ ). With the exception of capsulitis in the Humana dataset, all analyzed complications showed a statistically significant reduction $(p<0.05)$ following UKA compared to TKA (Tables 7 and 13). UKA implant survival was 87.7\% (95\% CI [0.861,0.894]) (Fig. 2) in the Humana dataset and $91.1 \%$ (95\% CI $[0.895,0.928])$ (Fig. 4; Table 11) at 8 years in the SAF dataset.
Post-operative opioid use was found to be less in patients undergoing UKA compared to those who underwent TKA. The queried databases provided prescribed days of opioids, which was used as a proxy for opioid use. Although we report higher MME in TKA patients compared to UKA patients, we were not able to provide statistical analysis for that finding. Opioids are used for postoperative pain control and then gradually tapered over the postoperative period. Many patients take opioids during outpatient physical therapy. Although the amount of opioid use may be significantly reduced during the physical therapy window compared to the days/weeks immediately following surgery, prescriptions for opioids would still be filled during the months after surgery when patients are undergoing physical therapy. Additionally, with a median length of 24 days for UKA and 34 days for TKA, the distribution is positively skewed. The maximum number of days of opioid prescriptions was 6,327 days for UKA and 8,191 days for TKA, which suggests that there may be a number of individuals in the study with longterm opioid prescriptions that raise the mean number of days of use. This is especially probable considering the reported $3^{\text {rd }}$ quartile of 48 days for UKA and 110 days for TKA. Fewer patients initiated opioid use postoperatively after UKA compared to TKA. Our results mirror those reported by Burn et al. that UKA was associated with a reduced risk of postoperative opioid use of 0.81 , (95\% [CI 0.73-0.90]) [4]. Additionally, a 2020 retrospective analysis evaluating patients who underwent UKA between 2015 and 2018 reported the opioid dosage was lower at $160.5 \pm 29.3 \mathrm{mg}$ for UKA and $186.1 \pm 46.8 \mathrm{mg}$ for TKA $(\mathrm{t}-2.969, p<0.01)[17]$.With increasing focus on decreasing opioid use, the usage profile for UKA may prove beneficial [18].

Another key finding of this study was that postoperative complications within the year following UKA procedures were significantly lower $(p<0.05)$ than those following TKA. This trend held true for almost all analyzed complications in both datasets. On average, TKA patients demonstrated poorer baseline health characteristics as measured by Elixhauser and Charlson comorbidity indexes. This is especially true for the SAF dataset which the median Elixhauser adjustment for TKA is 9 compared to 5 for UKA $(p<0.01)$. Our findings may be in part due to differences in baseline health, but we were not able to adjust for these differences in our statistical analysis. However, our findings are similar to other Medicare studies $[3,4,9]$, including a similar study of two large databases performed by Hansen et al. who reported that after adjusting for relevant patient comorbidities that UKA patients have less peri- operative complications than those having TKA [9]. 
Table 10 Time betwen UKA and TKA for patients undergoing conversion

\begin{tabular}{|c|c|c|c|c|c|c|c|c|c|}
\hline & \multirow{2}{*}{$\begin{array}{l}\text { Number of } \\
\text { UKA patients }\end{array}$} & \multicolumn{5}{|c|}{ UKA patients converted to TKA } & \multicolumn{3}{|c|}{ Average time between UKA and TKA } \\
\hline & & $\#$ & $\%$ & $p$ & $\mathbf{R R}$ & $95 \% \mathrm{Cl}$ & Days & $\Delta$ & $95 \% \mathrm{Cl}$ \\
\hline Total & 20,592 & 447 & $2.17 \%$ & - & - & - & 987.378 (SD 764.815) & - & - \\
\hline \multicolumn{10}{|c|}{ Age at UKA } \\
\hline$<70$ & 8,018 & 223 & $2.78 \%$ & - & - & - & 988.852 (SD 781.501) & - & - \\
\hline $70-79$ & 9,433 & 168 & $1.78 \%$ & $<0.0001$ & 0.6404 & $(0.5253,0.7806)$ & 980.262 (SD 729.328) & 8.590 & $(-13.921,31.101)$ \\
\hline$>80$ & 3,191 & 43 & $1.35 \%$ & $<0.0001$ & 0.4845 & $(0.3505,0.6698)$ & 806.558 (SD 768.786) & 182.294 & $(151.274,213.314)$ \\
\hline \multicolumn{10}{|l|}{ Gender } \\
\hline Female & 10,543 & 264 & $2.50 \%$ & - & - & - & 971.417 (SD 746.139) & - & - \\
\hline Male & 9,933 & 169 & $1.70 \%$ & $<0.0001$ & 0.6795 & $(0.5613,0.8226)$ & 965.391 (SD 785.201) & 6.026 & $(-14.9808,27.0328)$ \\
\hline
\end{tabular}

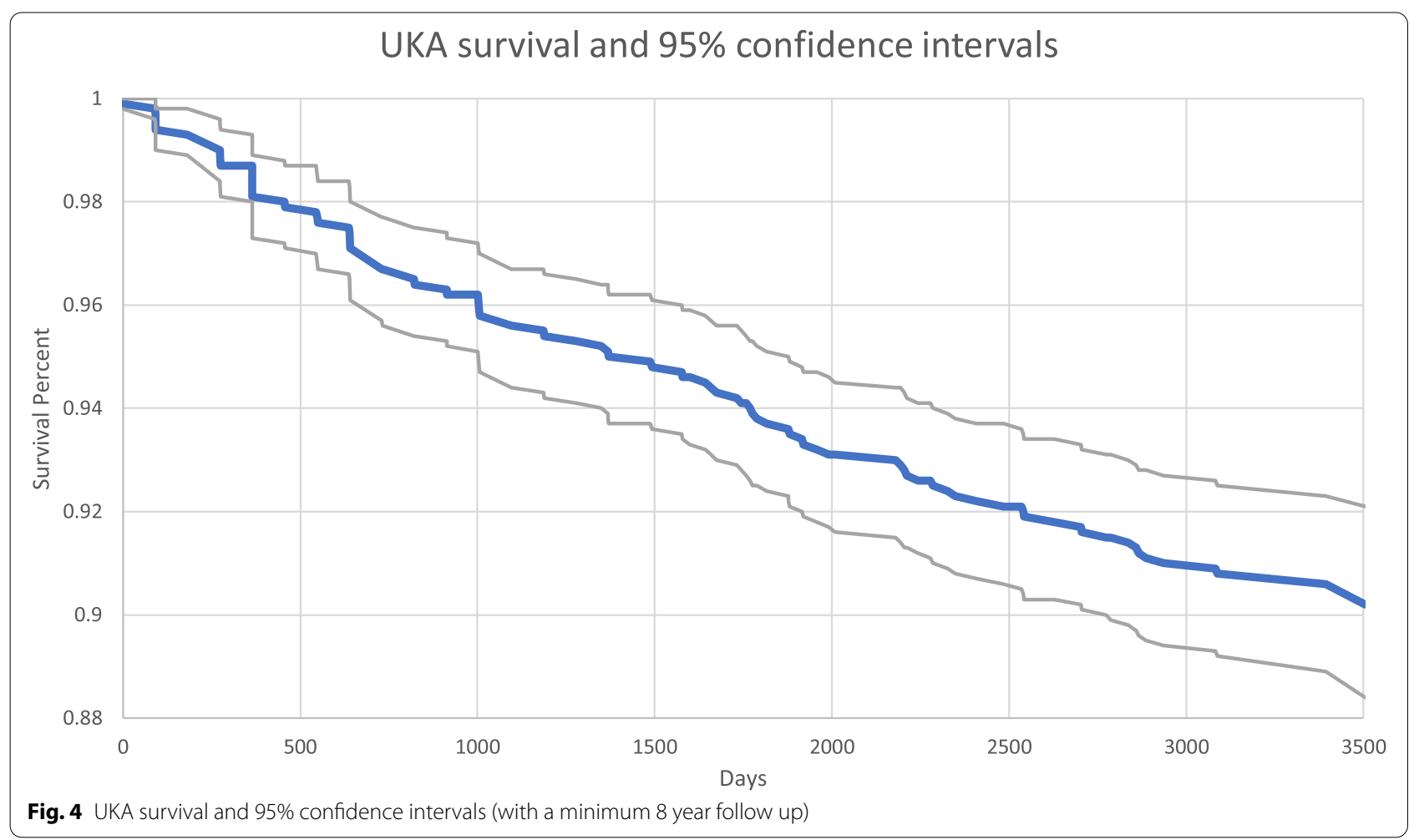

Table 118 year UKA implant survival by age and gender (with a minumum 8 year follow up)

\begin{tabular}{clll}
\hline & $\begin{array}{l}\text { Number of } \\
\text { UKA patients }\end{array}$ & $\begin{array}{l}\text { Convervsion } \\
\text { to TKA }\end{array}$ & 8 year survival $(\mathbf{9 5 \%} \mathbf{C l})$ \\
\hline $\begin{array}{l}\text { Total } \\
\text { Age }\end{array}$ & 1195 & 110 & $.911(.895-.928)$ \\
$<70$ & 466 & 54 & $.893(.865-.921)$ \\
$70-79$ & 585 & 49 & $.915(.892-.937)$ \\
$>80$ & 144 & 7 & $.958(.926-.992)$ \\
Gender & & & $.899(.876-.922)$ \\
Female & 673 & 70 & $.927(.905-.950)$ \\
Male & 522 & 40 & \\
\hline
\end{tabular}

Increasing UKA utilization in the Medicare population is likely multifactorial in nature and may be attributed to advances in biomaterials and implant design that reduce implant failure, increasing surgeon familiarity and expertise with the procedure, improved surgical instrumentation, and evolving surgical indications. Despite persistent debate as to superiority of fixed polyethylene bearings versus mobile polyethylene bearings or cemented versus uncemented UKA implants, overall survivability of UKA remains high and similar to that of TKA [12].

Advancements in surgical instrumentation, such as computer and robotic-assisted navigation, has also improved implant survivability [5, 19]. Expansion of 
Table 12 Time until revision for UKA and TKA

\begin{tabular}{|c|c|c|c|c|c|c|c|c|c|}
\hline & \multirow{2}{*}{$\begin{array}{l}\text { UKA } \\
\text { Patients }\end{array}$} & \multicolumn{5}{|c|}{ UKA revisions } & \multicolumn{3}{|l|}{ Avg. time between UKA and revision } \\
\hline & & \# & $\%$ & $p$ & $\mathrm{RR}$ & $95 \% \mathrm{Cl}$ & mean (SD) & $\Delta$ & $95 \% \mathrm{Cl}$ \\
\hline Total & 20,592 & 364 & $1.77 \%$ & - & - & - & 932.942 (SD 768.273) & - & - \\
\hline \multicolumn{10}{|c|}{ Age at UKA } \\
\hline$<70$ & 8,018 & 185 & $2.31 \%$ & - & - & - & 862.746 (SD 755.779) & - & - \\
\hline 70-79 & 9,433 & 140 & $1.48 \%$ & $<0.0001$ & 0.6432 & $(0.5175,0.7995)$ & 1039.486 (SD 778.513) & -176.74 & $(-199.296,-154.184)$ \\
\hline$>80$ & 3,191 & 36 & $1.13 \%$ & $<0.0001$ & 0.4890 & $(0.3430,0.6971)$ & 789.528 (SD 697.079) & 73.218 & $(42.137,104.299)$ \\
\hline \multicolumn{10}{|l|}{ Gender } \\
\hline Female & 10,543 & 224 & $2.12 \%$ & - & - & - & 981.920 (SD 773.567) & - & - \\
\hline \multirow[t]{3}{*}{ Male } & 9,933 & 135 & $1.36 \%$ & $<0.0001$ & 0.6397 & $(0.5176,0.7906)$ & 823.778 (SD 739.283) & 158.142 & $(137.420,178.864)$ \\
\hline & TKA & \multicolumn{5}{|c|}{ TKA revisions } & \multicolumn{3}{|l|}{ Avg. time between TKA and revision } \\
\hline & patients & $\#$ & $\%$ & $\mathrm{p}$ & $\mathrm{RR}$ & $95 \% \mathrm{Cl}$ & mean (SD) & $\triangle$ & $95 \% \mathrm{Cl}$ \\
\hline Total & 110,562 & 3,630 & $3.28 \%$ & - & - & - & 866.597 (SD 754.557) & - & - \\
\hline \multicolumn{10}{|c|}{ Age at TKA } \\
\hline$<70$ & 41,518 & 1,865 & $4.49 \%$ & - & - & - & 898.958 (SD 775.442) & - & - \\
\hline 70-79 & 52,129 & 1,525 & $2.93 \%$ & $<0.0001$ & 0.6513 & $(0.6094,0.6960)$ & 908.423 (SD 772.142) & -9.4650 & $(-19.220,0.290)$ \\
\hline$>80$ & 19,632 & 368 & $1.87 \%$ & $<0.0001$ & 0.4173 & $(0.3736,0.4660)$ & 718.584 (SD 669.883) & 180.3740 & $(167.529,193.219)$ \\
\hline \multicolumn{10}{|l|}{ Gender } \\
\hline Female & 71,394 & 2,279 & $3.19 \%$ & - & - & - & 896.808 (SD 761.672) & - & - \\
\hline Male & 38,214 & 1,211 & $3.17 \%$ & 0.8352 & 0.9927 & $(0.9269,1.0632)$ & 814.272 (SD 743.505) & 82.5360 & $(73.2201,91.8519)$ \\
\hline
\end{tabular}

Table 13 Incidence of complications within 12 months following TKA and UKA

\begin{tabular}{|c|c|c|c|c|c|c|c|}
\hline \multirow[t]{2}{*}{ Complication } & \multicolumn{2}{|l|}{ UKA } & \multicolumn{2}{|l|}{ TKA } & \multirow[t]{2}{*}{$p$-value } & \multirow[t]{2}{*}{$\mathbf{R R}$} & \multirow[t]{2}{*}{$95 \% \mathrm{Cl}$} \\
\hline & $\#$ & $\%$ & $\#$ & $\%$ & & & \\
\hline Acute kidney injury & 417 & $2.03 \%$ & 5,110 & $4.62 \%$ & $<0.0001$ & 0.4567 & $(0.4138,0.5041)$ \\
\hline Cardiac arrest & 47 & $0.23 \%$ & 617 & $0.56 \%$ & $<0.0001$ & 0.4111 & $(0.3057,0.5528)$ \\
\hline Deep vein thrombosis & 13 & $0.06 \%$ & 207 & $0.19 \%$ & $<0.0001$ & 0.3378 & $(0.1929,0.5915)$ \\
\hline Pneumonia & 449 & $2.18 \%$ & 5,984 & $5.41 \%$ & $<0.0001$ & 0.423 & $(0.3848,0.4651)$ \\
\hline Pulmonary embolism & 192 & $0.93 \%$ & 2,704 & $2.45 \%$ & $<0.0001$ & 0.3899 & $(0.3371,0.4510)$ \\
\hline Urinary tract infection & 1,742 & $8.46 \%$ & 22,678 & $20.51 \%$ & $<0.0001$ & 0.4905 & $(0.4683,0.5139)$ \\
\hline Wound dishiscence & 140 & $0.68 \%$ & 1,327 & $1.20 \%$ & $<0.0001$ & 0.5725 & $(0.4813,0.6810)$ \\
\hline Hematoma & 171 & $0.83 \%$ & 1,690 & $1.53 \%$ & $<0.0001$ & 0.5507 & $(0.4709,0.6441)$ \\
\hline Transfusion & 312 & $1.52 \%$ & 4,869 & $4.40 \%$ & $<0.0001$ & 0.3582 & $(0.3198,0.4013)$ \\
\hline Capsulitis & 106 & $0.51 \%$ & 1,381 & $1.25 \%$ & $<0.0001$ & 0.4169 & $(0.3423,0.5076)$ \\
\hline Nerve injury & 0 & $0.00 \%$ & 89 & $0.08 \%$ & $<0.0001$ & 0 & - \\
\hline
\end{tabular}

surgical indications has led to reconsidering traditional UKA indications for the current Medicare patient population [12]. Despite past thinking that UKA be reserved for low weight patients, a recent meta-analysis of 6 national registries and 31 clinical studies demonstrated no increased risk for poor outcomes or revision in patients with BMI over 30 [20]. Concomitant patellofemoral joint osteoarthritis and ACL-deficient knees, traditionally contra-indications to UKA, may no longer preclude patients from undergoing UKA as Hamilton et. al found similar functional scores in UKA patients with and without patellofemoral joint degeneration [8].

High implant survivability in the context of expanding surgical indications and advanced surgical instrumentation may explain our finding that UKA utilization accelerated most greatly during 2012 to 2014 as seen in the SAF dataset. In the SAF dataset, the greatest proportion of patients receiving UKA were in the 65-69-year-old age range, followed by patients 70-74 years old. Overall implant survivability with a minimum of eight years follow-up was found to be 87.7 and $91.1 \%$ in our respective 
datasets, which are similar to published UKA survival rates found in cohort studies [12]. Patients over 80 years of age demonstrated almost $96 \%$ implant survivability at eight years of follow-up, which may be due to lower functional demand anticipated in this age group. Though patients' resumption of activity was not studied in a database analysis, recent evidence suggests that $75 \%$ of UKA patients return to sport activity compared to $59 \%$ of TKA patients $(p<0.001)[16]$.

Results varied between the Humana and the SAF datasets, which demonstrates the difference in patient populations when evaluating the entire Medicare population in SAF compared to evaluating patients with Humana Medicare advantage. Humana Medicare advantage is a supplemental health insurance coverage product that may be purchased by Medicare participants that provides additional benefits to enrollees. Though the Humana dataset does not contain all Medicare patients, Humana has one of the largest number of Medicare Advantage enrollees, offering plans in $83 \%$ of all counties in the United States [11]. With socioeconomic status known as a social determinant of health, Humana Medicare Advantage participants may have higher baseline health characteristics than the average Medicare enrollee.

\section{Limitations}

Limitations to this study additionally include its retrospective review of a large database. Demographic variables are limited to those collected by the database. The use of ICD codes to determine postoperative complications does not allow for analysis of severity. Additionally, we were unable to analyze laterality of UKA (medial versus lateral) or type of UKA bearing (fixed versus mobile). Conversion to TKA did not specify laterality, therefore in our study it was possible for a patient to have UKA and then undergo TKA on their contralateral limb. This lack of specificity overestimates conversion to TKA, and actual UKA survivability in our study may be higher than identified due to this coding limitation. Patients greater than 80 years of age experienced better implant survival rates than younger aged Medicare patients, however, this survivability may be artificially high as death may precede these patients prior to UKA implant failure and conversion to TKA.

While the PearlDiver application permits identification and analysis of patients who were prescribed opioids after UKA or TKA, the database does not link opioid prescription with CPT code. Accordingly, it is possible that patients were prescribed opioids for reasons unrelated to their UKA or TKA procedure. However, given that the mean number of days for which opioids were prescribed were 186.1 days for TKA and 144.7 days for UKA, we feel confident that the prescriptions were provided for a discrete event, such as elective surgery. One additional limitation to our opioid analysis is our limitation of using number of prescribed days as a marker of opioid use, as the database does not specify dosage or compliance, which would have been a superior method to measure opioid consumption. Opioid use analysis was not possible in the SAF dataset due to lack of data.

\section{Conclusion}

Unicompartmental knee arthroplasty represents an increasingly utilized treatment for osteoarthritis in the Medicare population. Unicompartmental knee arthroplasty utilization may be comparatively advantageous to total knee arthroplasty due to reduced opioid use and complication rates after surgery.

\section{Appendix A: Elixhauser and Charlson Calculations}

The average Charlson Comorbidity Index and Elixhauser Comorbidity Index were calculated for the UKA and TKA groups. These indices were calculated automatically by the PearlDiver application using the following criteria, which has been adapted from the PearlDiver Research Manual Version 2.4.

- The Charlson Comorbidity Index is based on the following criteria:

O Apply 1 point for each of the following:

- Myocardial Infarction

- Congestive Heart Failure

- Peripheral Vascular Disease

- Cerebrovascular Disease

- Dementia

- COPD

- Connective Tissue Disease

- Peptic Ulcer Disease

- Diabetes Mellitus (uncomplicated)

- Liver Disease (Mild)

Apply 2 points for each of the following:

- Diabetes Mellitus (end-organ damage)

- Moderate to Severe Chronic Kidney Disease

- Hemiplegia (2 points)

- Leukemia (2 points)

- Malignant Lymphoma (2 points)

- Solid Tumor (not metastatic) 
Apply 3 points for patients with moderate to severe liver disease

Apply 6 points for each of the following:

- AIDS (6 points)

- Metastatic solid tumor

Apply the following points based on age:

- Age <50 years: 0 points

- Age 50-59 years: 1 points

- Age 60-69 years: 2 points

- Age 70-79 years: 3 points

- The Elixhauser Comorbidity Index is calculated based on the following criteria:

Apply 1 point for each of the following:

- Congestive heart failure

- Cardiac arrhythmias

- Valvular disease

- Pulmonary circulation Disorders

- Peripheral vascular disorders

- Hypertension, uncomplicated

- Hypertension, complicated

- Paralysis

- Other neurological disorders

- Chronic pulmonary disease

- Diabetes, uncomplicated

- Diabetes, complicated

- Hypothyroidism

- Renal failure

- Liver disease

- Peptic ulcer disease excluding bleeding

- AIDS/H1V

- Lymphoma

- Solid tumor without metastasis

- Rheumatoid arthritis/ collagen vascular diseases

- Coagulopathy

- Obesity

- Weight loss

- Fluid and electrolyte disorders

- Blood loss anemia

- Deficiency anemia

- Alcohol abuse

- Drug abuse

- Psychoses

- Depression

\section{Appendix B: Opioids}

Opioid use was defined as patients filing prescriptions for any of the following drugs. This list was provided by PearlDiver staff as acknowledged.

- HYDROCODONE BITARTRATE AND ACETAMINOPHEN

- MORPHINE SULFATE

- FENTANYL TRANSDERMAL SYSTEM

- METHADONE HYDROCHLORIDE

- CODEINE PHOSPHATE, PHENYLEPHRINE HYDROCHLORIDE

- HYDROCODONE BITARTRATE,

- OXYCODONE HYDROCHLORIDE AND ACETAMINOPHEN

- OXYCODONE HYDROCHLORIDE

- FENTANYL

- DIHYDROCODEINE BITARTRATE, BROMPHENIRAMINE MALEATE, PSEUDOEPHEDRINE HYDROCHLORIDE

- BUPRENORPHINE HYDROCHLORIDE

- HYDROMORPHONE HYDROCHLORIDE

- hYDROMORPHONE HCL

- FENTANYL CITRATE

- OXYCODONE

- OXYCODONE AND ACETAMINOPHEN

- BUPRENORPHINE HYDROCHLORIDE AND NALOXONE HYDROCHLORIDE DIHYDRATE

- OXYMORPHONE HYDROCHLORIDE

- CODEINE PHOSPHATE, GUAIFENESIN AND PSEUDOEPHEDRINE HYDROCHLORIDE

- HYDROCODONE BITARTRATE AND IBUPROFEN

- MEPERIDINE HCL

- TAPENTADOL

- MEPERIDINE HYDROCHLORIDE

- hydROCODONE BITARTRATE, ACETAMINOPHEN

- HYDROCODONE POLISTIREX AND CHLORPHENIRAMINE POLISTIREX

- TAPENTADOL HYDROCHLORIDE

- HYDROCODONE BITARTRATE

- CODEINE PHOSPHATE AND GUAIFENESIN

- NORETHINDRONE AND ETHINYL ESTRADIOL TABLETS

- bUPRENORPHINE AND NALOXONE

- BUPRENORPHINE HYDROCHLORIDE AND NALOXONE HYDROCHLORIDE

- CODEINE PHOSPHATE, DEXCHORPHENIRAMINE MALEATE, PHENYLEPHRINE HYDROCHLORIDE 
- FENTANYL CITRATE, BUPIVACAINE HCL

- MORPHINE SULFATE AND NALTREXONE HYDROCHLORIDE

- BUPRENORPHINE HYDROCHLORIDE, NALOXONE HYDROCHLORIDE

- HYDROCODONE BITARTRATE, IBUPROFEN

- CODEINE PHOSPHATE, PROMETHAZINE HYDROCHLORIDE, AND PHENYLEPHRINE HYDROCHLORIDE

- MORPHINE

- BUPRENORPHINE HCL

- FENTANYl bUCCAL

- CODEINE PHOSPHATE AND APAP

- CODEINE PHOSPHATE, GUAIFENESIN, PSEUDOEPHEDRINE HYDROCHLORIDE

- MORPHINE SUFATE

- CODEINE PHOSPHATE, PHENYLEPHRINE HYDROCHLORIDE, CHLORPHENIRAMINE MALEATE

- BUPRENORPHINE HYDROCHLORIDE SUBLINGUAL

- HYDROCODONE BITARTRATE AND CHLORPHENIRAMINE MALEATE

- CODEINE SULFATE

- HYDROCODONE BITATRATE AND ACETAMINOPHEN

- HYDROCODONE BITARTRATE, AND CHLORPHENIRAMINE MALEATE

- HYDROCODONE BITARTRATE, CHLORPHENIRAMINE MALEATE AND PSEUDOEPHEDRINE HYDROCHLORIDE

- MORPHINE BASE

- BUPRENORPHINE

- HYDROCODONE BITARTATE AND ACETAMINOPHEN

- OXYCODONE HYDROCHLORIDE, ACETAMINOPHEN

- HYDROCODONE BITARTRATE, CHLORPHENIRAMINE MALEATE, AND PSEUDOEPHEDRINE HYDROCHLORIDE

- HYDROCODONE POLISTIREX AND CHLORPHENIRAMINE POLISITREX

- OXYCODONE AND ASPIRIN

- DIHYDROCODEINE BITARTRATE, PHENYLEPHRINE HYDROCHLORIDE, PYRILAMINE MALEATE

- CODEINE PHOSPHATE, PHENYLEPHRINE HYDROCHLORIDE, BROMPHENIRAMINE MALEATE

- OXYCODONE HCL CONTROLLED-RELEASE

- CODEINE PHOSPHATE
- CODEINE PHOSPHATE, DEXBROMPHENIRAMINE MALEATE, PSEUDOEPHEDRINE HYDROCHLORIDE

- CODEINE PHOSPHATE AND GUAIFENESIN AND PSEUDOPHEDRINE

- hYdROCODONE BITARTRATE, CHLORPHENIRAMINE MALEATE, PSEUDOEPHEDRINE HYDROCHLORIDE

- MORPHINE HYDROCHLORIDE

- HYDROCODONE, ACETAMINOPHEN

- MORPHINE SULFATE EXTENDED RELEASE

- HYDROCODONE BITARTRATE, ACETAMINOPHEN, .GAMMA.-AMINOBUTYRIC ACID

- CODEINE PHOSPHATE, PHENYLEPHRINE HYDROCHLORIDE AND PYRILAMINE MALEATE

- CODEINE PHOSPHATE, PSEUDOEPHEDRINE HYDROCHLORIDE, BROMPHENIRAMINE MALEATE

- CODEINE PHOSPHATE, PSEUDOEPHEDRINE HYDROCHLORIDE, PYRILAMINE MALEATE

- OXYCODONE AND ASPIRIN TABLETS

- CODEINE PHOSPHATE AND CHLORPHENIRAMINE MALEATE

- DIHYDROCODEINE BITARTRATE, PHENYLEPHRINE HYDROCHLORIDE, AND GUAIFENESIN

- CODEINE PHOSPHATE, GUAIFENESIN

- DIHYDROCODEINE BITARTRATE, GUAIFENESIN

- OXYCODONE HYDROCHLORIDE AND IBUPROFEN

- CODEINE PHOSPHATE, GUAIFENESIN, AND PSEUDOEPHEDRINE HYDROCHLORIDE

- HYDROCODONE BITARTRATE AND PSEUDOEPHEDRINE HYDROCHLORIDE

- CODEINE PHOSPHATE, PSEUDOEPHEDRINE HCL, CHLORCYCLIZINE HCL

- OXYCODONE HYDCHLORIDE

- DIHYDROCODEINE BITARTRATE, BROMPHENIRAMINE MALEATE, AND PHENYLEPHRINE HYDROCHLORIDE

- HYDROCODONE BITARTRATE AND ACETAMINPHEN

- MORPHINE SULFATE ORAL SOLUTION

- OXYCODONE HYDROCHLORIDE AND ASPIRIN

- CODEINE PHOSPHATE AND PYRILAMINE MALEATE

- HYDROCODONE POLISTIREX AND CHLORPHENIRAMINE POLISTIREX EXTENDED RELEASE ORAL SUSPENSION 
- DIHYDROCODEINE BITARTRATE, PHENYLEPHRINE HYDROCHLORIDE, GUAIFENESIN

- CODEINE PHOSPHATE, BUTAlBITAL, CAFFEINE, AND ACETAMINOPHEN CAPSULE

- DIHYDROCODEINE BITARTRATE, ACETAMINOPHEN AND CAFFEINE

- HYDROCODONE BITARTRATE WITH ACETAMINOPHEN

- CODEINE PHOSPHATE, PHENYLEPHRINE HYDROCHLORIDE AND DIPHENHYDRAMINE HYDROCHLORIDE

- OXYCODONE HCL AND ACETAMINOPHEN

- CODEINE BASE

- HYDROCODONE BITARTRATE, PSEUDOEPHEDRINE HYDROCHLORIDE

- CODEINE PHOSPHATE, PSEUDOEPHEDRINE HYDROCHLORIDE

- HYDROCODONE, ACETAMINOPHEN, .GAMMA.-AMINOBUTYRIC ACID

- MEPERIDINE HYDROCHLORIDE AND PROMETHAZINE HYDROCHLORIDE

- CODEINE PHOSPHATE, CHLORCYCLIZINE HCL

- HYDROCODONE BITARTATE AND HOMATROPINE METHYLBROMIDE

- CODEINE PHOSPHATE, gUIAFENESIN, PSEUDOEPHEDRINE HCL

- CODEINE PHOSPHATE / GUAIFENESIN

- HYDROCODONE BITARTRATE AND GUAIFENESIN

- CODEINE PHOSPHATE/GUAIFENESIN/PSEUDOEPHEDRINE HYDROCHLORIDE

- MORPHINE TINCTURE

\section{Appendix C: Complications}

Complications were defined by their respective ICD-9 and ICD-10 codes in cohorts predefined by the PearlDiver application. The codes used for each complication are listed below, adapted from the PearlDiver Research Manual Version 2.4.

- Acute Kidney Injury: ICD-9-D-5845,ICD-9-D5846,ICD-9-D-5847, ICD-9-D-5848, ICD-9-D5849,ICD-10-D-N17:ICD-10-D-N179

- Cardiac Arrest: ICD-9-D-4275,ICD-9-D-42741,ICD10-D-I46:ICD-10-D-I469

- Deep Vein Thrombosis (DVT): ICD-9-D-4532,ICD9-D-4533,ICD-9-D-4534,ICD-9-D-45382,ICD-9D-45384,ICD-9-D-45385,ICD-9-D-45386,ICD-10D-I26:ICD-10-D-I2699
- Nerve Injury: ICD-9-D-9550,ICD-9-D-9551,ICD9-D-9552,ICD-9-D-9553,ICD-9-D-9554,ICD-9D-9555,ICD-9-D-9556,ICD-9-D-9557,ICD-9-D9558,ICD-9-D-9559,ICD-9-D-9074,ICD-10-DS440,ICD-10-DS4400,ICD-10-D-S4400XA, ICD10-D-S4400XD,ICD-10-D-S4400XS,ICD-10-DS4401,ICD-10-DS4401XA,ICD-10-D-S4401XD,ICD10 - D - S 4401 X S , IC D - 10 - D - S 4 4 02, IC D - 10 D-S4402XA,ICD-10-D S4402XD,ICD-10-DS4402XS,ICD-10-D-S441,ICD-10-D-S4410,ICD10 - D - S 4410XA, IC D - 10 - D -S 4410X D, ICD 10-D-S4410X S, ICD - 10-D-S4411, ICD - 10-DS 4411X A, ICD - 10-D - S 4 411 XD, ICD - 10 - D S4411XS,ICD-10-DS4412,ICD-10-D-S4412XA,ICD10-D-S4412XD,ICD-10-D-S4412XS,ICD-10-DS442,ICD-10-D-S4420,ICD-10-D-S4420XA,ICD10-D-S4420XD,ICD-10-D-S4420XS,ICD-10-DS4421,ICD-10-D-S4421XA,ICD-10-DS4421XD,ICD10 - D - S 4421 X S , ICD - 10 - D - S 4 422, IC D - 10 D-S 4422XA, ICD - 10 - D -S 4422X D, ICD - 10 DS4422XS,ICD-10-D-S443,ICD-10-D-S4430,ICD10 - D - S 4430XA , IC D - 10 - D - S 4430X D, IC D 10-D-S4430XS, ICD - 10-D-S4431, ICD-10-DS 4431X A, ICD - 10 - D - S 4 431 XD, ICD - 10 - D S4431XS,ICD-10-D-S4432,ICD-10-DS4432XA,ICD10-D-S4432XD,ICD-10-D-S4432XS,ICD-10-DS444,ICD-10-D-S4440,ICD-10-D-S4440XA,ICD10 - D - S 4 440X D, IC D - 10 - D - S 4 440XS, ICD 10-D-S4441, ICD-10-D-S4441 XA, ICD - 10-DS4441XD,ICD-10-DS4441XS,ICD-10-D-S4442,ICD10-D-S4442XA,ICD-10-D-S4442XD,ICD-10-DS4442XS, ICD-10-D-S445, ICD-10-D-S4450,ICD10-D-S4450XA,ICD-10-D-S4450XD,ICD-10-DS4450XS,ICD-10-D-S4451,ICD-10-DS4451XA,ICD10 - D - S4 451X D, ICD - 10 - D-S4451X S, ICD - 1 0 - D - S 4 452, ICD - 10 - D - S 4 4 52 X A , IC D - 10 DS4452X D, ICD-10-D-S4452X S, ICD-10-DS448,ICD-10-D-S448X,ICD-10-D-S448X1,ICD10-D-S448X1A,ICD-10-D-S448X1D,ICD-10-D-S448X1S,ICD-10-D-S448X2,ICD-10-D-S448X2A,ICD$10-D-S 448 X 2 D, I C D-10-D S 448 X 2 S, I C D-10$ D-S448X 9, ICD - 10-D-S448 X 9A, ICD - 10 - D S448X9D,ICD-10-D-S448X9S,ICD-10-DS449, ICD10-D-S4490, ICD-10-D-S4490XA, ICD - 10-D S4490XD,ICD-10-D-S4490XS,ICD-10-D-S4491, ICD-10-D-S4491XA, ICD-10-D-S4491XD,ICD10 - D-S 4491X S, ICD - 10-D - S4492, ICD - 10 - D S4492XA,ICD-10-DS4492XD,ICD-10-D-S4492XS

- Pneumonia: ICD-9-D-4800:ICD-9-D-4809,ICD9-D-481,ICD-9-D-4820,ICD-9-D-4821,ICD-9-D48230,ICD-9-D-48231,ICD-9-D-48232,ICD-9-D48239,ICD-9-D-48240,ICD-9-D-48241,ICD-9-D48242, ICD-9-D-48249, ICD-9-D-48281,ICD-9- 
D-48282,ICD-9-D-48283,ICD-9-D-48284,ICD9-D-48289,ICD-9-D-4829,ICD-9-D-4830,ICD9-D-4831, ICD-9-D-4838, ICD-9-D - 4841, ICD9-D-4843,ICD-9-D-4845,ICD-9-D-4846,ICD-9D-4847,ICD-9-D-4848,ICD-9-D-485,ICD-9-D486,ICD-10-D-J12:ICD-10-D-J189

- Pulmonary Embolism: ICD-9-D-4151:ICD-9-D4159,ICD-10-D-I26:ICD-10-D-I269

- Urinary Tract Infection: ICD-9-D-5990,ICD-10-DN390

- Disruption of Wound: ICD-9-D-99830,ICD-9D-99831,ICD-9-D-99832,ICD-9-D-99833,ICD10 - D T 8130 X A , ICD - 10 - D - T 8130 X D, ICD 10 - D - T 8130 X S , ICD - 10 - D - T 8131 XA, ICD 10-D-T8131XD,ICD-10-DT8131XS, ICD-10D - T 8132 X A , I CD - 10 - D - T 8132 XD, ICD - 10 D - T 8132 X S , I C D - 10 - D - T 8133 X A , I CD - 10 DT8133XD,ICD-10-D-T8133XS

- Hematoma: ICD-9-D-99811,ICD-9-D-99812,ICD-9D-99813,ICD-10-D-D7801, ICD-10-D-D7802,ICD10-D-D7821, ICD-10-D-D7822, ICD-10-D-E3601, ICD-10-D-E3602, ICD-10-D-E89810, ICD-10-DE89811,ICD-10-D-G9731, ICD-10-D-G9732, ICD10-D-G9751, ICD-10-D-G9752, ICD-10-D-H59111, ICD-10-DH59112,ICD-10-D-H59113， ICD-10-DH59119, ICD-10-D-H59121， ICD-10-D-H59122, ICD-10-D-H59123,ICD-10-D-H59129, ICD-10-DH59311, ICD-10-D-H59312, ICD-10-D-H59313, ICD-10-D-H59319, ICD-10-DH59321,ICD-10-DH59322, ICD-10-D-H59323, ICD-10-D-H59329, ICD-10-D-H9521, ICD-10-D-H9522, ICD-10-DH9541, ICD-10-D-H9542, ICD-10-D-I97410, ICD10-D-I97411， ICD-10-D-I97418， ICD-10-D-I9742, ICD-10-D-I97610, ICD-10-D-I97611, ICD-10-DI97618, ICD-10-D-I97620, ICD-10-D-J9561, ICD-10D-J9562, ICD-10-D-J95830, ICD-10-D-J95831, ICD10-D-K9161, ICD-10-D-K9162, ICD-10-D-K91840, ICD-10-D-K91841,ICD-10-D-L7601, ICD-10-DL7602, ICD-10-D-L7621, ICD-10-D-L7622, ICD-10D-M96810, ICD-10-DM96811,ICD-10-D-M96830, ICD-10-D-M96831, ICD-10-D-N9961, ICD-10-DN9962, ICD-10-D-N99820, ICD-10-D-N99821, ICD10-D-T888XXA

- Transfusion: ICD-9-P-9904,ICD-10-P-3023,ICD10-P-30230AZ,ICD - 10-P-30230G0, ICD - 10 P-30230G2,ICD - 10 - P-30230G3,ICD - 10 - P 30230G4,ICD-10-P-30230H0,ICD-10-P-30230H1,ICD-10-P-30230J0,ICD-10-P-30230J1, ICD $10-\mathrm{P}-30230 \mathrm{~K} 0, \mathrm{ICD}-10-\mathrm{P}-30230 \mathrm{~K} 1, \mathrm{ICD}-10$ P- $30230 \mathrm{~L} 0, \mathrm{ICD}-10$ - P - $30230 \mathrm{~L} 1, \mathrm{ICD}-10$ - P 30230M0,ICD-10-P-30230M1,ICD-10-P-30230N0,ICD-10-P-30230N1,ICD-10-P-30230P0,ICD10 - P - 30230 P 1, I C D - 10 - P - 30230 Q 0, IC D -
$10-\mathrm{P}-30230 \mathrm{Q} 1, \mathrm{IC}$ D - 10 - P - $30230 \mathrm{R} 0, \mathrm{IC}$ 10 - P - $30230 \mathrm{R} 1$, ICD - 10 - P - 30230 S 0, ICD 10 - P - $30230 \mathrm{~S} 1$, I C D - 10 - P - $30230 \mathrm{~T} 0$, I C D $10-\mathrm{P}-30230 \mathrm{~T} 1, \mathrm{I} C \mathrm{C}-10-\mathrm{P}-30230 \mathrm{~V} 0, \mathrm{ICD}-$ $10-\mathrm{P}-30230 \mathrm{~V} 1, \mathrm{ICD}-10-\mathrm{P}-30230 \mathrm{~W} 0$, ICD $10-\mathrm{P}-30230 \mathrm{~W} 1, \mathrm{ICD}-10-\mathrm{P}-30230 \mathrm{X} 0$, I CD $10-\mathrm{P}-30230 \mathrm{X} 2, \mathrm{ICD}-10-\mathrm{P}-30230 \mathrm{X} 3$, ICD $10-\mathrm{P}-30230 \mathrm{X} 4, \mathrm{IC} D-10-\mathrm{P}-30230 \mathrm{Y} 0, \mathrm{I} C \mathrm{C}-$ 10 - P - $30230 Y 2, I C D-10-P-30230 Y 3, I C D$ 10 - P - 30230 Y 4, ICD - 10 - P - 30233 A Z, I CD 10 - P - 30233 G0, I CD - 10 - P- 30233 G 2, I CD 10 - P-30233G3,ICD-10-P-30233G4,ICD - 10 P - 30233 H0, I C D - 10 - P - 30233 H 1, I C D - 10 P - 30233 J 0, I C D - 10 - P - 30233 J 1, I C D - 10 - P 30233K0,ICD-10-P-30233K1,ICD-10-P-30233L0,ICD-10-P-30233L1, ICD-10-P-30233M0,ICD$10-\mathrm{P}-30233 \mathrm{M} 1, \mathrm{ICD}-10-\mathrm{P}-30233 \mathrm{~N} 0, \mathrm{ICD}-10$ P - 30233N1, ICD - 10 - P - 30233 P 0, ICD - 10 - P 30233P1,ICD-10-P-30233Q0,ICD-10-P-30233Q1,ICD-10-P-30233R0,ICD-10-P-30233R1,ICD$10-\mathrm{P}-30233 \mathrm{~S} 0, \mathrm{I} C \mathrm{D}-10-\mathrm{P}-30233 \mathrm{~S} 1$, ICD $10-\mathrm{P}-30233 \mathrm{~T} 0, \mathrm{ICD}-10-\mathrm{P}-30233 \mathrm{~T} 1, \mathrm{ICD}-$ $10-\mathrm{P}-30233 \mathrm{~V} 0, \mathrm{ICD}-10-\mathrm{P}-30233 \mathrm{~V} 1, \mathrm{ICD}-$ $10-\mathrm{P}-30233 \mathrm{~W} 0, \mathrm{ICD}-10-\mathrm{P}-30233 \mathrm{~W} 1, \mathrm{ICD}-$ $10-\mathrm{P}-30233$ X 0, ICD - $10-\mathrm{P}-30233$ X 2, ICD $10-\mathrm{P}-30233 \mathrm{X} 3, \mathrm{IC} D-10-\mathrm{P}-30233 \mathrm{X} 4$, ICD $10-\mathrm{P}-30233 \mathrm{Y} 0, \mathrm{ICD}-10-\mathrm{P}-30233 \mathrm{Y} 2, \mathrm{ICD}-10$ P-30233Y3, ICD - $10-\mathrm{P}-30233$ Y 4, ICD - 10 - P 30240 A Z, ICD - 10 - P - 30240 G 0, ICD - 10 - P $30240 \mathrm{G} 2$, ICD - 10 - P - $30240 \mathrm{G} 3$, I CD - 10 - P 30240 G 4, I C D - 10 - P - 30240 H 0, I C D - 10 - P 30240H1,ICD-10-P-30240J0,ICD-10-P-30240J1,ICD10 - P - $30240 \mathrm{~K} 0$, IC D - 10 - P - $30240 \mathrm{~K} 1$, I C D 10 - P - $30240 \mathrm{~L} 0, \mathrm{ICD}-10$ - P - $30240 \mathrm{~L} 1$, ICD $10-\mathrm{P}-30240 \mathrm{M0}, \mathrm{ICD}-10-\mathrm{P}-30240 \mathrm{M} 1$, ICD $10-\mathrm{P}-30240 \mathrm{~N} 0, \mathrm{I} C \mathrm{D}-10-\mathrm{P}-30240 \mathrm{~N} 1$, I C D - 10 - P-30240P0,ICD - 10-P-30240P1, ICD - 10 P - 30240 Q 0, ICD - 10 - P - 30240 Q 1, ICD - 10 P-30240R0, ICD - 10 - P - $30240 \mathrm{R} 1$, ICD - 10 - P 30240S0,ICD-10-P-30240S1,ICD-10-P-30240T0,ICD - 10-P-30240T 1,ICD-10-P-30240V0,ICD $10-\mathrm{P}-30240 \mathrm{~V} 1, \mathrm{ICD}-10$ - P-30240W 0, ICD - 10 P-30240W 1, ICD - 10 - P - 30240 X0, ICD - 10 - P 30240X2,ICD-10-P-30240X3,ICD-10-P-30240X4,ICD-10-P-30240Y0,ICD-10-P-30240Y2,ICD10 - P-30240Y3, ICD - 10 - P - 30240 Y 4, ICD - 10 P- 30243 AZ, ICD - 10 - P - 30243 G0, ICD - 10 - P $30243 G 2, I C D-10$ - P-30243G3, ICD - 10 - P - 30 243G4,ICD-10-P-30243H0,ICD-10-P-30243H1,ICD10 - P - 30243 J 0, I C D - 10 - P - 30243 J 1, I C D $10-\mathrm{P}-30243 \mathrm{~K} 0, \mathrm{ICD}-10-\mathrm{P}-30243 \mathrm{~K} 1$, I CD 10 - P - 30243 L 0, I C D - 10 - P - 30243 L 1, I CD 10 - P - $30243 \mathrm{M} 0, \mathrm{ICD}-10$ - P - $30243 \mathrm{M} 1$, ICD - 
10 - P - $30243 \mathrm{~N} 0$, I C D - 10 - P - $30243 \mathrm{~N} 1$, ICD 10-P-30243P0, ICD - 10-P-30243P 1, ICD-10P - 30243 Q 0, ICD - $10-P-30243$ Q1, ICD - 10 P - 30243 R0, ICD - 10 - P - 30243 R 1, ICD - 10 P-30243S 0, ICD-10-P-30243S1, ICD-10-P 30243 T 0, ICD - 10 - P - 30243 T 1, IC D - 10 - P 30243 V 0, ICD - $10-\mathrm{P}-30243 \mathrm{~V} 1, \mathrm{ICD}-10$ - P 30243 W 0, ICD - 10 - P - 30243 W 1, ICD - 10 - P 30243 X 0, ICD - $10-\mathrm{P}-30243$ X 2, ICD - 10 - P 30243 X 3, ICD - 10 - P - 30243 X 4, ICD - 10 - P 30243 Y 0, IC D - 10 - P - 30243 Y 2, IC D - 10 - P 30243Y3,ICD-10-P-30243Y4,ICD-10-P-30250G0,ICD-10-P-30250G1,ICD-10-P-30250H0,ICD10-P-30250H1, ICD-10-P-30250J0, ICD-10P-30250J1, ICD - 10 - P - 30250 K0, ICD - 10 - P 30250K1,ICD-10-P-30250L0,ICD-10-P-30250L1,ICD-10-P-30250M0,ICD-10-P-30250M1,ICD10-P-30250N0, ICD-10-P-30250N1, ICD-10P-30250P0, ICD - 10-P-30250 P 1, ICD-10 - P 30250 Q 0, ICD - $10-\mathrm{P}-30250 \mathrm{Q} 1$, ICD - 10 - P - 3 0250R0,ICD-10-P-30250R1,ICD-10-P-30250S0,ICD10-P-30250S1, ICD-10-P-30250T 0, ICD-10P-30250T 1, ICD - 10 - P - 30250V0, ICD - 10 P-30250V1, ICD-10-P-30250W0, ICD-10 P-30250W 1, ICD - 10 - P-30250X 0, ICD - 10 P-30250X1, ICD-10-P-30250Y0,ICD-10-P 30250 Y 1, ICD - 10 - P - 30253 G 0, IC D - 10 - P 30253 G 1, ICD - 10 - P - 30253 Ho, ICD - 10 - P 30253H1,ICD-10-P-30253J0,ICD-10-P-30253J1,ICD$10-\mathrm{P}-30253 \mathrm{~K} 0, \mathrm{ICD}-10$ - P-30253K1, ICD - 10 P-30253L 0, ICD - 10 - P-30253L1, ICD - 10 - P 30253M0,ICD-10-P-30253M1,ICD-10-P-30253N0,ICD-10-P-30253N1, ICD-10-P-30253P0, ICD10-P-30253P1, ICD-10-P-30253Q0, ICD-10P-30253Q1, ICD - 10-P-30253R0, ICD - 10-P 30253R1,ICD-10-P-30253S0,ICD-10-P-30253S1,ICD-10-P-30253T0,ICD-10-P-30253T1,ICD10-P-30253V0,ICD-10-P-30253V1, ICD - 10 P-30253W0,ICD-10-P-30253W1,ICD-10-P30253X0,ICD-10-P-30253X1,ICD-10-P-30253Y0,ICD-10-P-30253Y1,ICD-10-P-30260G0,ICD10 - P - $30260 \mathrm{G} 1$, ICD - 10 - P - $30260 \mathrm{H} 0$, ICD 10 - P - $30260 \mathrm{H} 1$, IC D - 10 - P - 30260 J0, ICD $10-\mathrm{P}-30260 \mathrm{~J} 1, \mathrm{ICD}-10-\mathrm{P}-30260 \mathrm{~K} 0, \mathrm{ICD}-$ $10-\mathrm{P}-30260 \mathrm{~K} 1, \mathrm{ICD}-10-\mathrm{P}-30260 \mathrm{~L} 0, \mathrm{ICD}$ $10-\mathrm{P}-30260 \mathrm{~L} 1, \mathrm{ICD}-10-\mathrm{P}-30260 \mathrm{M} 0$, ICD $10-\mathrm{P}-30260 \mathrm{M} 1, \mathrm{ICD}-10-\mathrm{P}-30260 \mathrm{~N} 0$, ICD $10-\mathrm{P}-30260 \mathrm{~N} 1, \mathrm{ICD}-10-\mathrm{P}-30260 \mathrm{P} 0$, ICD $10-\mathrm{P}-30260 \mathrm{P} 1$, ICD - 10 - P - $30260 \mathrm{Q} 0$, ICD 10 - P - $30260 \mathrm{Q} 1$, ICD - 10 - P - $30260 \mathrm{R} 0$, ICD $10-P-30260 R 1, I C D-10-P-30260 S 0, I C D$ $10-\mathrm{P}-30260 \mathrm{~S} 1$, ICD - 10 - P - $30260 \mathrm{~T} 0$, ICD 10 - P-30260T 1, ICD - 10 - P-30260V0, ICD -
- 10 - P - $30260 \mathrm{~V} 1, \mathrm{ICD}-10-\mathrm{P}-30260 \mathrm{~W} 0$, ICD 10-P-30260W 1, ICD-10-P-30260X0,ICD-10P-30260X1, ICD - 10-P-30260Y0,ICD - 10 - P 30260Y1,ICD-10-P-30263G0,ICD-10-P-30263G1,ICD-10-P-30263H0, ICD-10-P-30263H1, ICD10 - P - 30263J0, IC D - 10 - P - 30263J1, ICD - 10 P-30263K0,ICD - $10-\mathrm{P}-30263 \mathrm{~K} 1, \mathrm{ICD}-10$ - P 30263L0,ICD-10-P-30263L1,ICD-10-P-30263M0,ICD-10-P-30263M1,ICD-10-P-30263N0,ICD10 - P - $30263 \mathrm{~N} 1, \mathrm{ICD}-10$ - P - 30263 P 0, ICD $10-\mathrm{P}-30263 \mathrm{P} 1, \mathrm{IC} D-10-\mathrm{P}-30263 \mathrm{Q} 0, \mathrm{ICD}$ $10-P-30263 Q 1, I C D-10-P-30263 R 0, I C D$ 10-P-30263R1, ICD-10-P-30263S0, ICD-10P-30263S1, ICD - 10-P-30263T0, ICD - 10-P 30263 T 1, ICD - 10 - P - 30263 V 0, IC D - 10 - P $30263 \mathrm{~V} 1, \mathrm{ICD}-10$ - P - $30263 \mathrm{~W} 0$, ICD - 10 - P 30263W1,ICD-10-P-30263X0,ICD-10-P-30263X1, ICD-10-P-30263Y0,ICD-10-P-30263Y1,ICD10 - P - $30273 \mathrm{H} 1$, ICD - 10 - P - 30273 J 1, IC D 10 - P - $30273 \mathrm{~K} 1$, ICD - 10 - P - $30273 \mathrm{~L} 1$, IC D $10-\mathrm{P}-30273 \mathrm{M} 1, \mathrm{ICD}-10-\mathrm{P}-30273 \mathrm{~N} 1, \mathrm{IC} \mathrm{D}-$ $10-\mathrm{P}-30273 \mathrm{P} 1, \mathrm{ICD}-10-\mathrm{P}-30273 \mathrm{Q} 1, \mathrm{ICD}-$ $10-\mathrm{P}-30273 \mathrm{R} 1, \mathrm{ICD}-10-\mathrm{P}-30273 \mathrm{~S} 1, \mathrm{ICD}-$ $10-\mathrm{P}-30273 \mathrm{~T} 1, \mathrm{ICD}-10-\mathrm{P}-30273 \mathrm{~V} 1, \mathrm{ICD}-$ $10-\mathrm{P}-30273 \mathrm{~W} 1, \mathrm{ICD}-10-\mathrm{P}-30277 \mathrm{H} 1, \mathrm{ICD}-$ $10-\mathrm{P}-30277 \mathrm{~J} 1, \mathrm{IC} D-10-\mathrm{P}-30277 \mathrm{~K} 1$, ICD $10-\mathrm{P}-30277 \mathrm{~L} 1, \mathrm{ICD}-10-\mathrm{P}-30277 \mathrm{M} 1, \mathrm{ICD}-$ $10-\mathrm{P}-30277 \mathrm{~N} 1, \mathrm{ICD}-10-\mathrm{P}-30277 \mathrm{P} 1, \mathrm{ICD}$ $10-\mathrm{P}-30277 \mathrm{Q} 1, \mathrm{IC} \mathrm{D}-10-\mathrm{P}-30277 \mathrm{R} 1, \mathrm{ICD}$ $10-\mathrm{P}-30277 \mathrm{~S} 1, \mathrm{ICD}-10-\mathrm{P}-30277 \mathrm{~T} 1, \mathrm{ICD}-$ -10-P-30277V1,ICD-10-P-30277W1,ICD-10-P30280B1,ICD-10-P-30283B1

- Capsulitis: ICD-9-D-7260,ICD-9-D-71951,ICD-10D-M7500,ICD-10-D-M7501,ICD-10-D-M7502

\begin{abstract}
Abbreviations
CPT: Current Procedural Terminology; DVT: Deep vein thrombosis; HIPAA: Health Insurance Portability and Accountability Act; ICD-9: International Classification of Diseases, Ninth Revision; ICD-10: International Classification of Diseases, Tenth Revision; OA: Osteoarthritis; SAF: Medicare Standard Analytic File; SD: Standard deviation; TKA: Total knee arthroplasty; UKA: Unicompartmental knee arthroplasty.
\end{abstract}

\section{Acknowledgements}

The authors of this study would like to express their appreciation for Jordan Baker of the University of Kansas Medical Center Department of Biostatistics and Data Science for his assistance with statistical analysis and Scott Ellison and the staff of PearlDiver Technologies for their assistance in coding and data extraction while using the PearlDiver application.

\section{Conflict of interest}

None of the authors have any relevant conflicts of interest or disclosures pertaining to this research. 


\section{Informed consent}

Informed consent was not obtained as this study uses de-identified data that is publicly available.

\section{Authors' contributions}

Our manuscript represents the product of a collaborative effort. All authors contributed to the study design, data collection, and data analysis, as well as manuscript drafting and editing. BM is the primary author and orthopedic fellow responsible for all aspects of study and manuscript. JA is a co-author and medical student responsible for background, study design, analysis, and review. DR is a co-author and orthopedic resident responsible for all aspects of study and manuscript. AT is a co-author and orthopedic research assistant responsible for database management, analysis, and review. SM is a co-author and orthopedic attending responsible for background, study design, analysis, and review. JPS is a co-author and orthopedic attending responsible for background, study design, analysis, and review. BV is the primary investigator and orthopedic attending responsible for background, study design, analysis, and review. The author(s) read and approved the final manuscript.

\section{Funding}

The article processing charges related to the publication of this article were supported by The University of Kansas (KU) One University Open Access Author Fund sponsored jointly by the KU Provost, KU Vice Chancellor for Research \& Graduate Studies, and KUMC Vice Chancellor for Research and managed jointly by the Libraries at the Medical Center and KU-Lawrence.

\section{Availability of data and materials}

The datasets analyzed during the current study are available in the PearlDiver application/repository, available with subscription at http://www.pearldiver inc.com/.

\section{Declarations}

\section{Ethics approval and consent to participate}

Institutional Review Board approval was not required since this study uses de-identified data that is publicly available.

\section{Consent for publication}

Not applicable.

\section{Competing interests}

The authors declare that they have no competing interests directly related to this study.

Received: 4 August 2021 Accepted: 17 August 2021

Published online: 09 November 2021

\section{References}

1. Bolognesi MP, Greiner MA, Attarian DE, Watters TS, Wellman SS, Curtis LH et al (2013) Unicompartmental knee arthroplasty and total knee arthroplasty among Medicare beneficiaries, 2000 to 2009. J Bone Joint Surg Am. 95(22):e174

2. Borus T, Thornhill T (2008) Unicompartmental knee arthroplasty. J Am Acad Orthop Surg 16(1):9-18

3. Brown NM, Sheth NP, Davis K, Berend ME, Lombardi AV, Berend KR et al (2012) Total knee arthroplasty has higher postoperative morbidity than unicompartmental knee arthroplasty: a multicenter analysis. J Arthroplasty 27(8 Suppl):86-90

4. Burn E, Weaver J, Morales D, Prats-Uribe A, Delmestri A, Strauss VY et al (2019) Opioid use, postoperative complications, and implant survival after unicompartmental versus total knee replacement: a populationbased network study. The Lancet Rheumatology 1(4):e229-e236

5. Chowdhry M, Khakha RS, Norris M, Kheiran A, Chauhan SK (2017) Improved survival of computer-assisted unicompartmental knee arthroplasty: 252 cases with a minimum follow-up of 5 years. J Arthroplasty 32(4):1132-1136

6. Dettoni F, Bonasia DE, Castoldi F, Bruzzone M, Blonna D, Rossi R (2010) High tibial osteotomy versus unicompartmental knee arthroplasty for medial compartment arthrosis of the knee: a review of the literature. lowa Orthop J 30:131-140

7. Foran JR, Brown NM, Della Valle CJ, Berger RA, Galante JO (2013) Longterm survivorship and failure modes of unicompartmental knee arthroplasty. Clin Orthop Relat Res 471(1):102-108

8. Hamilton TW, Pandit HG, Jenkins C, Mellon SJ, Dodd CAF, Murray DW (2017) Evidence-based indications for mobile-bearing unicompartmental knee arthroplasty in a consecutive cohort of thousand knees. J Arthroplasty 32(6):1779-1785

9. Hansen EN, Ong KL, Lau E, Kurtz SM, Lonner JH (2019) Unicondylar knee arthroplasty has fewer complications but higher revision rates than total knee arthroplasty in a study of large United States databases. J Arthroplasty 34(8):1617-1625

10. Heyse TJ, Khefacha A, Peersman G, Cartier P (2012) Survivorship of UKA in the middle-aged. Knee 19(5):585-591

11. Jacobson GF, Damico M, Neuman T. 2019 Medicare advantage 2020 spotlight: first look - data note - 9365 |The Henry J. Kaiser Family Foundation.

12. Jennings JM, Kleeman-Forsthuber LT, Bolognesi MP (2018) Medial Unicompartmental Arthroplasty of the Knee. J Am Acad Orthop Surg 27(166):176

13. Kozinn SC, Scott R (1989) Unicondylar knee arthroplasty. J Bone Joint Surg Am 71(1):145-150

14. Menendez ME, Neuhaus V, van Dijk CN, Ring D (2014) The Elixhauser comorbidity method outperforms the Charlson index in predicting inpatient death after orthopaedic surgery. Clin Orthop Relat Res 472(9):2878-2886

15. Nwachukwu BU, McCormick FM, Schairer WW, Frank RM, Provencher MT, Roche MW (2014) Unicompartmental knee arthroplasty versus high tibial osteotomy: United States practice patterns for the surgical treatment of unicompartmental arthritis. J Arthroplasty 29(8):1586-1589

16. Papalia R, Zampogna B, Torre G, Diaz Balzani LA, Vasta S, Papalia G et al (2020) Return to sport activity in the elderly patients after unicompartmental knee arthroplasty: a systematic review and meta-analysis. J Clin Med. 9(6):1756

17. Pei Z, Ding ZT, Li Z, Guan ZP. [Comparison of the early efficacy of unicompartmental and total knee arthroplasty in patients with medial compartmental osteoarthritis of the knee: a propensity score matching study]. Zhonghua Wai Ke Za Zhi. 2020;58(6):452-456. Chinese. https://doi. org/10.3760/cma.j.cn112139-20200322-00244. PMID: 32498485.

18. Trasolini NA, McKnight BM, Dorr LD (2018) The opioid crisis and the orthopedic surgeon. J Arthroplasty. 33(11):3379-82.e1

19. Vakharia RM, Sodhi N, Cohen-Levy WB, Vakharia AM, Mont MA, Roche MW (2019) Comparison of patient demographics and utilization trends of robotic-assisted and non-robotic-assisted unicompartmental knee arthroplasty. J Knee Surg 34:621-627

20. van der List JP, Chawla H, Zuiderbaan HA, Pearle AD (2016) The role of preoperative patient characteristics on outcomes of unicompartmental knee arthroplasty: a meta-analysis critique. J Arthroplasty 31(11):2617-2627

\section{Publisher's Note}

Springer Nature remains neutral with regard to jurisdictional claims in published maps and institutional affiliations. 